OPEN ACCESS

Edited by:

Rob Harcourt,

Macquarie University, Australia

Reviewed by:

Gail Schofield,

Queen Mary University of London,

United Kingdom

Yves Le Gall,

Centre de Bretagne, Institut Français de Recherche pour l'Exploitation de la

Mer, France

${ }^{*}$ Correspondence:

Isabella M. F. Kratzer

kratzer.isabella@gmail.com

Specialty section

This article was submitted to

Marine Megafauna,

a section of the journal

Frontiers in Marine Science

Received: 13 February 2020

Accepted: 15 June 2020

Published: 03 July 2020

Citation:

Kratzer IMF, Schäfer I, Stoltenberg A, Chladek JC, Kindt-Larsen L, Larsen F and

Stepputtis D (2020) Determination

of Optimal Acoustic Passive

Reflectors to Reduce Bycatch

of Odontocetes in Gillnets.

Front. Mar. Sci. 7:539.

doi: 10.3389/fmars.2020.00539

\section{Determination of Optimal Acoustic Passive Reflectors to Reduce Bycatch of Odontocetes in Gillnets}

\author{
Isabella M. F. Kratzer ${ }^{1,2 *}$, Ingo Schäfer ${ }^{3}$, Arne Stoltenberg³, Jérôme C. Chladek', \\ Lotte Kindt-Larsen ${ }^{2}$, Finn Larsen ${ }^{2}$ and Daniel Stepputtis ${ }^{1}$ \\ ${ }^{1}$ Institute of Baltic Sea Fisheries, Thünen Institute, Rostock, Germany, ${ }^{2}$ National Institute of Aquatic Resources, Technical \\ University of Denmark, Lyngby, Denmark, ${ }^{3}$ Bundeswehr Technical Center for Ships and Naval Weapons, Maritime \\ Technology and Research, Eckernförde, Germany
}

The need to minimize bycatch of toothed whales (odontocetes) in gillnets has long been recognized, because they are often top predators and thus essential to ecosystem resilience. It is likely that a key to achieving this goal is the improvement of gillnet acoustic visibility, because these species use underwater sonar for orientation. Previous work on increasing gillnet detectability for echolocating animals by making the nets more recognizable has been based on trial and error, without understanding the fundamental acoustic properties of the tested modifications. Consequently, these studies have produced mixed and sometimes contradictory results. We systematically identified small, passive reflective objects that can improve the visibility of gillnets at a broad range of frequencies, i.e., for many odontocetes. We simulated the acoustic reflectivity of a wide range of materials in different shapes, sizes, and environmental conditions, with a focus on polymer materials. We verified the simulation results experimentally and calculated detection distances of the selected modifications. For example, if $8 \mathrm{~mm}$ acrylic glass spheres are attached to the net at intervals smaller than $0.5 \mathrm{~m}$, the spheres have the same target strength (TS) at $130 \mathrm{kHz}$ as the most recognizable part of a gillnet, the floatline. Modifications of the netting material itself, e.g., using barium sulfate additives, do not substantially increase the acoustic reflectivity of the net.

Keywords: bycatch, odontocetes, resonance, target strength, acrylic glass, gillnet

\section{INTRODUCTION}

At least since Biblical times, whales, or cetaceans, have been an order of animals fascinating to humans. Over time, the focus has shifted from hunting to coexistence and onto conservation of these marine mammals (Harrop, 2003). Nowadays, cetaceans are protected by national and international agreements (Marine Mammal Protection Act, 1972; ASCOBANS, 1992; EEC, 1992; Accobams, 2001), and only a small number of countries still practices commercial whaling. In addition to humankind's ethical obligation to avoid their unintentional killing, whales are often top predators and thus support the resilience of ecosystems (Estes et al., 2011). To keep ecosystems stable, as well as ecosystem services that provide us with food, security, and general well-being (Millennium Ecosystem Assessment, 2005), it is necessary to provide suitable protection for top consumers. The many reasons that threaten whales include climate change, habitat degradation, 
increased aquatic noise, pollution, and overfishing (Reeves et al., 2003; IWC, 2019). Furthermore, unwanted bycatch of marine megafauna, including whales, has been pinpointed as one of the driving forces in species reduction (Lewison et al., 2014). The International Whaling Commission has acknowledged bycatch as the "greatest immediate threat for cetaceans globally" (IWC, 2018).

Static fishing nets, such as gillnets, belong to the most frequently used fishing gears owing to their low cost, easy handling, and their practicality on the large number of small fishing vessels (He, 2010). Despite being highly size selective, having little direct impact on the seabed (Savina et al., 2018), and being more fuel efficient than active gears, gillnets have been criticized for the bycatch of higher taxa species, especially birds and aquatic mammals. They are considered to be one of the drivers in severely reducing the number of individuals of some cetacean species (Burkhart and Slooten, 2003; Crespo, 2018) and even driving them to the verge of extinction (D'agrosa et al., 2000; Turvey et al., 2007).

Cetaceans are divided into two groups: toothed whales (odontocetes) and baleen whales (mysticetes). Both groups use sound as a communication tool, but only for odontocetes has it been proven that they echolocate actively, which could allow them to avoid gillnets. Despite their echolocation ability, it is still unknown why odontocetes entangle in gillnets in the first place. At least harbor porpoises (Phocoena phocoena, L.) are able to detect gillnet structures from a distance in quiet conditions (Nielsen et al., 2012). There are several hypotheses why odontocetes entangle: (a) they do not echolocate continuously (Dawson, 1991); (b) they echolocate in a different direction or lock in on another target (Au and Jones, 1991; Mackay, 2011); (c) they mistake gillnets, owing to the gillnets' faint echo, for an object they can penetrate and fail to recognize it as an obstacle (Goodson, 1997); and (d) the echo of the net is masked. In this study, we follow the hypothesis that odontocetes are able to detect gillnets from a short distance, but do not realize they are an obstacle. We aim to improve both the perceived image as well as increase the detection range to avoid collision.

There have been several attempts to develop gillnets that reduce the bycatch of odontocetes with mixed and sometimes contradictory results. Studies have demonstrated reduced target catch (Larsen et al., 2007), decreased bycatch for certain species (Perrin et al., 1994; Trippel et al., 2003; Larsen et al., 2007), but also no decrease in bycatch for other species (Perrin et al., 1994; Bordino et al., 2013). Many attempts have been based on trialand-error approaches without sufficient understanding of the acoustic properties of the modified gears and the requirements of the fishery. For instance, lower target catches or impeded handling and safety hazards caused by modifications (Hembree and Harwood, 1987; Peddemors et al., 1991) hamper the voluntary uptake of modified gillnets.

There are two options to modify the acoustic reflectivity of gillnets: changing the netting itself by using a different kind of filament, and adding objects with strong echo properties. If the latter option is chosen, the object needs to fulfill certain requirements to succeed in reducing bycatch and be adopted by the fishery. The object needs to be acoustically omnidirectional, not impede handling of the net, and have little or no effect on net behavior; the last is essential to keeping fish catches constant. Therefore, a spherical object is suitable, because spheres have the same properties from every direction and the density of the object is preferably close to seawater to avoid an increase or decrease in buoyancy of the net. Furthermore, the object must be relatively small to facilitate handling and minimize the need for additional storage space, especially on board small vessels.

These requirements suggest several possible gillnet modifications. Consequently, a systematic approach to the issue is a valuable alternative to a large-scale, trial-and-error field trial. Here, for the first time, we systematically simulated the target strength (TS) of potential modifications to gillnets that can substantially increase the acoustic visibility of gillnets, such as modified filaments and added objects. In a parametric study, we have simulated a large number of different objects to identify the ideal objects that would allow odontocetes to perceive gillnets early on and classify them as obstacles. We simulated the acoustic characteristics of the objects in a wide range of frequencies to cover many odontocete species and thus allow the identification of optimal objects for different species, resulting in a wide application of the modification. Selected simulations were confirmed by measurements in an acoustic tank. Furthermore, a standard gillnet was equipped with one of the promising objects, and sonar images were taken of both a modified and a standard gillnet. We used harbor porpoises as a model species for odontocetes, because they are affected by gillnet fisheries worldwide (Trippel et al., 1996; Vinther and Larsen, 2004; Read et al., 2006; Koschinski and Pfander, 2009; Tonay, 2016) and are a well-studied species. Thus, in the third part of the study, we predict the distance at which harbor porpoises, an endangered species in the Eastern Baltic Sea (Helcom, 2013), should be able to perceive a modified net.

\section{MATERIALS AND METHODS}

\section{Simulation of Target Strength}

Target strength is one of the standard parameters used to describe the acoustic reflectivity of different objects, including nets (Pence, 1986; Au and Jones, 1991; Mooney et al., 2004). It can be defined as:

$$
T S=20 \times \log _{10}\left(\frac{p_{r}}{p_{i}}\right)
$$

where $\mathrm{p}_{\mathrm{r}}$ is the sound pressure of the object relative to $1 \mathrm{~m}$ from the target, and $\mathrm{p}_{\mathrm{i}}$ is the incident sound pressure of the signal at the target. The unit is $\mathrm{dB}$ re $1 \mathrm{~m}$ (MacLennan et al., 2002; Mooney et al., 2007).

We used the software COMSOL Multiphysics (Comsol Multiphysics ${ }^{\circledR}$, 2018) to conduct a parameter study. We numerically solved the Helmholtz equation, which is used to describe the acoustic pressure field in fluids, and derived TS values for a large variety of objects and sound frequencies under different environmental conditions. The simulation environment was surrounded by a perfectly matched layer 
(PML), which absorbs all outgoing waves without reflection (see Supplementary Information). The simulation environment can be reduced to $2 \mathrm{D}$, because cylinders and spheres are rotationally symmetric.

The following parameter categories were modified in the simulation: the geometry of the object, material characteristics of the object, characteristics of the surrounding medium, and sound frequency (Table 1). The geometrical characteristics of the objects included shape (solid and hollow spheres, cylinders, cuboids, radar reflectors, half spheres) and size (diameter, wall thickness). Here, we present only results for solid and hollow spheres as well as cylinders, because other shapes do not fulfill the defined requirements, especially omnidirectionality and small size.

The material characteristics of the object are Young's modulus (E) as a measure for elasticity and density $(\rho)$ of the material. Although the object density should ideally be close to seawater, we have used a much larger range of densities to evaluate a broad range of possibilities. We chose material densities starting at $1000 \mathrm{~kg} / \mathrm{m}^{3}$, because synthetic materials less than $1000 \mathrm{~kg} / \mathrm{m}^{3}$ are usually foams, which are inhomogeneous and thus difficult to simulate. The alternative material with densities less than $1000 \mathrm{~kg} / \mathrm{m}^{3}$ are wooden products; these are usually anisotropic, so they have different characteristics depending on the direction. Furthermore, their mechanical properties are difficult to control, because the properties of natural materials change with the environmental conditions they grow in, making it virtually impossible to ensure the same characteristics for each object.

The characteristics of the surrounding medium are density and speed of sound, which act as a proxy for the environmental conditions in water, i.e., temperature and salinity. Generally, speed of sound and medium density were approximated at $1500 \mathrm{~m} / \mathrm{s}$ and $1000 \mathrm{~kg} / \mathrm{m}^{3}$, respectively, unless otherwise specified in Supplementary Information.

\section{Verification of Selected Simulation Results}

To verify the simulation results, we experimentally measured the acoustic properties of selected objects [table-tennis ball (TT ball), steel sphere $25.5 \mathrm{~mm}$, acrylic glass spheres 6.4 and $9.6 \mathrm{~mm}$ ] in an acoustic tank $(5 \mathrm{~m} \times 5 \mathrm{~m} \times 3 \mathrm{~m})$. These objects were attached to a fishing line and consecutively suspended from the surface to be placed at $1.50 \mathrm{~m}$ depth and at an approximate distance of $1 \mathrm{~m}$ from the acoustic transducer. The objects were ensonified using a

TABLE 1 | Overview of parameters and their ranges used for parameter study using COMSOL.

\begin{tabular}{lcc}
\hline Parameter & Range & Unit \\
\hline Frequency & $1-200$ & $\mathrm{kHz}$ \\
Diameter $(\mathrm{d})$ & $0.25-60$ & $\mathrm{~mm}$ \\
Wall thickness & $1-2.8$ & $\mathrm{~mm}$ \\
Young's modulus (E) & $0.1-10$ & $\mathrm{GPa}$ \\
Object density $(\rho)$ & $1000-8000$ & $\mathrm{~kg} / \mathrm{m}^{3}$ \\
Salinity (Sal) & $0-31$ & $\mathrm{psu}$ \\
Temperature $(T)$ & $0-18$ & ${ }^{\circ} \mathrm{C}$
\end{tabular}

$\mathrm{B} \& \mathrm{~K} 8105$ spherical hydrophone; the signals were received using a Reson TC4014 spherical hydrophone (sampling rate $4 \mathrm{MS} / \mathrm{s}$ with a $200 \mathrm{kHz}$ low-pass Besselfilter; amplification + $50 \mathrm{~dB}$ ). The signal was a sweep between 60 and $120 \mathrm{kHz}(184 \mathrm{~dB}$ re $1 \mu \mathrm{Pa}$ source level).

\section{Sonar Imaging of Standard and Modified Nets}

To visualize the potential effect of small objects with high acoustic reflectivity attached to a gillnet, we took an acoustic image using a standard scientific echosounder (SIMRAD EK60) of both a modified and a standard gillnet. We glued $8 \mathrm{~mm}$ acrylic glass spheres to a standard gillnet $(140 \mathrm{~mm}$ stretched mesh size, $2 \mathrm{~m}$ rigged height) at a distance of $0.3 \mathrm{~m}$ between the spheres. Both the modified gillnet and the standard gillnet without spheres were stretched consecutively between two small boats, and the net was placed in the center of the sonar beam underneath RV Clupea. Echograms were made using 38 and $120 \mathrm{kHz}$ hull-mounted transducers. Sonar data were visualized in SonarData Echoview (Echoview Software Pty Ltd, 2015).

\section{Potential Detection Distances}

The applicability of gillnet modifications depends largely on their effect on echolocating odontocetes. We modeled the potential detection distances of the modified net using the harbor porpoise as a model. In this case, we used $8 \mathrm{~mm}$ acrylic glass spheres as the modification and virtually distributed them over a gillnet at different distances between spheres. The sphere-sphere distances ranged from 0.1 to $0.7 \mathrm{~m}$.

First, we calculated the maximum possible TS of spheres in an ensonified area of $0.36 \mathrm{~m}^{2}$ for each sphere-sphere distance. This area was chosen to stay consistent with Kastelein et al. (2000), who determined TS and detection ranges for various gillnets and gillnet components when $0.36 \mathrm{~m}^{2}$ are ensonified using echosounder with a similar beam angle as a harbor porpoise. The number of spheres that are simultaneously ensonified depends on the distance between spheres in a given area. For each distance between spheres, we fit the maximum number of spheres in the ensonified area while maintaining equal distance between the spheres. For example, applying a distance of $0.1 \mathrm{~m}$ between the spheres, results in 37 spheres in the ensonified area, whereas $0.7 \mathrm{~m}$ distance results in a single sphere in the ensonified area.

To calculate the maximum possible TS for a given number of spheres, we solved Equation 1 for $\mathrm{p}_{\mathrm{i}} / \mathrm{p}_{\mathrm{r}}$ :

$$
T S_{n \text { spheres }}=20 \times \log _{10}\left(n \times\left(\frac{p_{i}}{p_{r}}\right)\right)
$$

which results in:

$$
T S_{n \text { spheres coherent }}=20 \times \log _{10}(n)+T S_{\text {single sphere }}
$$

where $n$ is the number of spheres and TS single_sphere $_{\text {is the TS of }}$ one sphere. This corresponds to the coherent addition of the TS of $n$ spheres, which is the maximum possible value. In addition 
to the maximum, we also calculated the most likely mean TS by incoherent addition (Kinsler et al., 2000):

$$
T S_{n \text { spheres incoherent }}=10 \times \log _{10}(n)+T S_{\text {single sphere }}
$$

Detection distances were modeled based on the method described in Kastelein et al. (2000). We calculated potential detection distances for an ensonified area of $0.36 \mathrm{~m}^{2}$ with different distances $(0.1-0.7 \mathrm{~m})$ between spheres. The distance between spheres determines the number $(n)$ of spheres that are simultaneously ensonified. The following equation was solved for R:

$$
\begin{aligned}
& 40 \times \log _{10} R+2 \times \alpha \times R+T S_{n \text { spheres }} \\
= & 40 \times \log _{10} R_{r e f}+2 \times \alpha \times R_{r e f}+T S_{r e f}
\end{aligned}
$$

where $\mathrm{R}$ is the distance at $90 \%$ detection probability for the investigated object. The reference $90 \%$ detection range $\left(R_{\text {ref }}\right)$ for an object with reference TS $\left(\mathrm{TS}_{\mathrm{ref}}\right)$ is given by Kastelein et al. (1999). Here, we assumed an acoustic absorption coefficient of seawater $\alpha=0.038 \mathrm{~dB} / \mathrm{m}\left(\mathrm{T}=8^{\circ} \mathrm{C}\right.$, Sal $=35 \mathrm{ppt}, \mathrm{ph}=8$, depth $=50 \mathrm{~m}$, Ainslie and McColm, 1998).

\section{RESULTS}

\section{Simulation of Target Strength Identification of Relevant Parameters, Narrowing Parameter Ranges}

First, we simulated the TS of spheres in a large range of diameter (5-60 mm), elasticity (0.1-9.6 GPa), material density (1000$8000 \mathrm{~kg} / \mathrm{m}^{3}$ ), and combinations thereof in order to identify the relevant parameters and their ranges to obtain maximum TS at small sphere size for given frequencies.

Figure 1 shows the TS of solid spheres depending on the elasticity (Young's modulus) and material density, exemplarily at $130 \mathrm{kHz}$. In Figures 1A-C, spheres between 5 and $60 \mathrm{~mm}$ are shown for three exemplary densities $\left(1000,1180,8000 \mathrm{~kg} / \mathrm{m}^{3}\right)$, representative of the extreme ends of the parameter range and an approximation of seawater density. Figures 1D-F show the interplay between material density and elasticity for three sizes of small spheres $(5,10,15 \mathrm{~mm})$. Other densities and frequencies are found in the Supplementary Information.

Target strength is positively correlated with diameter of the sphere (Figures 1A-C). Nevertheless, the overall pattern is not homogeneous. Resonance and extinction effects can be seen for many parameter combinations resulting in outstandingly strong and weak TS for given parameter combinations. For instance, relatively high TS can be achieved for small spheres $(10 \mathrm{~mm}$ sphere, $3.6 \mathrm{GPa}, 1180 \mathrm{~kg} / \mathrm{m}^{3}, 130 \mathrm{kHz}$ ), whereas large spheres can have very weak TS owing to extinction (40 mm sphere, $4.6 \mathrm{GPa}$, $1180 \mathrm{~kg} / \mathrm{m}^{3}, 130 \mathrm{kHz}$ ). Sphere size combined with the material properties are crucial to identifying optimal reflectors. High TS of small spheres $(d<20 \mathrm{~mm}$, Figures 1A-C) is achieved for a Young's modulus between approximately 2.5 and $4.5 \mathrm{GPa}$. This range of elasticity for small spheres is also suitable over the entire frequency range used for echolocation by many odontocetes (50-150 kHz; see Supplementary Information).

If existing standard materials are considered, the material density cannot exceed $3000 \mathrm{~kg} / \mathrm{m}^{3}$, because Young's modulus and density are positively correlated (Figure 2). Even if a material existed with a high density and low Young's modulus, the increase in density would not necessarily positively affect TS of small spheres (Figures 1D-F for $130 \mathrm{kHz}$; additional figures in Supplementary Information). Based on these general investigations over a broad range of parameter characteristics, suitable echo targets could be chosen for any desired application.

To find additional objects to be mounted on gillnets to increase the acoustical detectability of these gillnets, we further investigated spheres of a density close to seawater. This narrows potential materials to polymers (Figure 2, reddish area). Several polymers are in the suitable parameter range and therefore could be used for gillnet modification. We chose to concentrate our effort on acrylic glass (PMMA) because it best fits the simulated parameters and has further advantages, such as transparency and being easily attachable to a gillnet with an acrylic adhesive with the same material properties as the sphere itself. In the additional simulations, we identified a minimum sphere size needed to obtain resonance effects, resulting in high TS at a specific frequency and simulated spheres on a higher diameter resolution scale. This simulation approach was conducted for a large range of frequencies, allowing us to identify speciesspecific resonators.

In the literature, the Young's modulus for acrylic glass is given as approximately 3.3 GPa (Abts, 2016); this value, however, does not account for changes in Young's modulus at high frequencies. Therefore, we have adapted the value to $4.8 \mathrm{GPa}$, based on our own measurements at high frequencies.

\section{Minimum Size for Resonance Effect at Different Frequencies}

For small spheres, resonance effects, rather than pure geometrical reflection, are responsible for high TS, especially at low material densities (Figure 1). This effect can lead to large differences in TS, even if the object parameters change little. Because of the large variation in TS resulting from changes in sphere diameter, the TS was simulated at a finer resolution of the diameter range across frequencies for acrylic glass (Figure 3). This allows the determination of the minimum size of a sphere with resonance characteristics and the exact size of a sphere that would be the ideal resonator at the main echolocation frequency of a given odontocete species. The TS reference used and illustrated in Figure 3 is $-50 \mathrm{~dB}$, which corresponds approximately to the TS of gillnets (Au and Jones, 1991; Perrin et al., 1994; Kastelein et al., 2000; Mooney et al., 2004). Furthermore, at least harbor porpoises could detect nets with $-50 \mathrm{~dB}$ TS from approximately $5 \mathrm{~m}$ (Kastelein et al., 2000). As a rule of thumb, the TS of an additional object needs to be greater than the reference TS to improve the acoustic detectability and so to potentially increase the detection range of gillnets for odontocetes.

The graphs (Figure 3) are shown for both the literature value of elasticity for acrylic glass (Figures $\mathbf{3 A}, \mathbf{B}$ ), and the adapted 

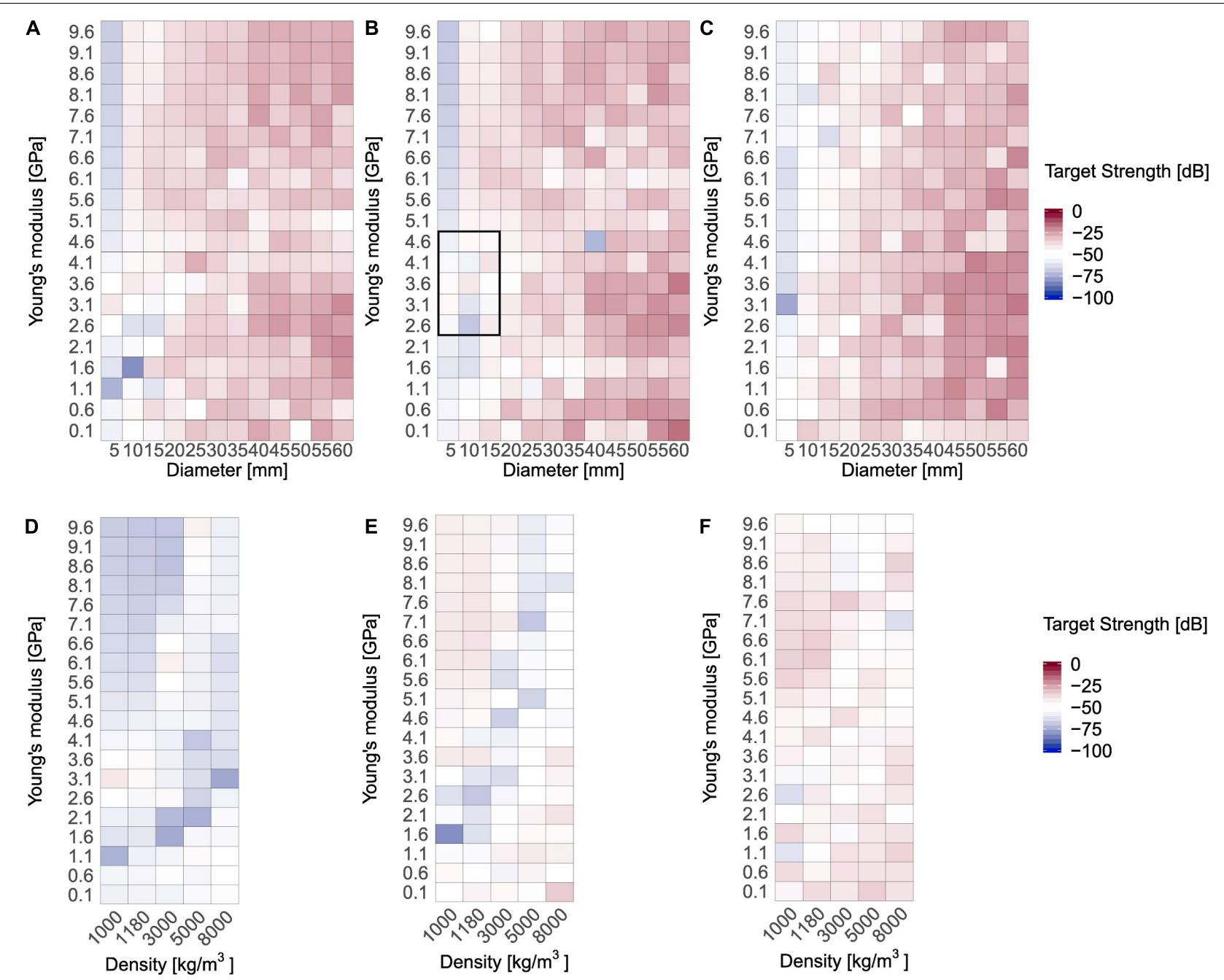

Target Strength $[\mathrm{dB}]$

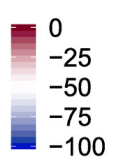

FIGURE 1 | (A) Target strength of solid spheres at $\rho=1000 \mathrm{~kg} / \mathrm{m}^{3} ;$ (B) $\rho=1180 \mathrm{~kg} / \mathrm{m}^{3}$; and (C) $\rho=8000 \mathrm{~kg} / \mathrm{m}^{3}$ at $130 \mathrm{kHz}$. Each cell represents one simulation, color ranges from strong echo (red) to low echo (blue). The box in (B) shows the most promising region of objects: small, relatively large echo, and density of seawater; (D-F) show the interaction between material density and elasticity for three small sphere sizes: (D) $5 \mathrm{~mm}$, (E) $10 \mathrm{~mm}$, (F) $15 \mathrm{~mm}$. Additional frequencies and material densities are available in Supplementary Information.

high-frequency elasticity value (Figures 3C,D). Figure 3 is given in two different color scales. Figures $3 \mathrm{~A}, \mathrm{C}$ uses the same color scale ( 0 to $-100 \mathrm{~dB})$ used by Figure 1 for reasons of comparison. Additionally, the color scale was adapted to highlight resonance peaks (Figures 3B,D; red areas), and areas of acoustic extinction with very low TS (Figures $\mathbf{3 B}, \mathbf{D}$; blue areas), and easier identification of the reference TS (Figures 3B,D; white areas).

Spheres smaller than $3.4 \mathrm{~mm}$ in diameter have no potential to improve the TS of a gillnet (TS $<-50 \mathrm{~dB}$ ), even at higher frequencies. Additionally, to get resonance effects at frequencies lower than $32 \mathrm{kHz}$, a sphere larger than $20 \mathrm{~mm}$ is required.

\section{Effects of Salinity and Temperature on Target Strength}

Odontocetes occur in many bodies of water across the world. Therefore, we simulated the influence of salinity and temperature on TS of solid acrylic spheres by adapting the density and sound speed of the surrounding medium according to the parameters specified in the Supplementary Information. We calculated the TS for spheres between 5 and $12 \mathrm{~mm}$ in $1 \mathrm{~mm}$ increments and frequencies between 10 and $200 \mathrm{kHz}$. For example, the TS for an $8 \mathrm{~mm}$ acrylic sphere $(E=4.8 \mathrm{GPa})$ at $130 \mathrm{kHz}$, where the maximum difference in TS for this sphere size is $1.10 \mathrm{~dB}$ and the mean difference $0.44 \mathrm{~dB}$ (Table in Supplementary Information). At $130 \mathrm{kHz}$, across all diameters and simulated environmental conditions, the maximum difference in TS was $3.22 \mathrm{~dB}$ and occurred within the $10 \mathrm{~mm}$ spheres.

\section{TS of Sphere With Small Cut for Attachment to Net}

One potential way to attach a sphere to a net is to cut it to the middle and attach it to the net using an acrylic glass adhesive, using the same material the sphere is made of. To quantify 


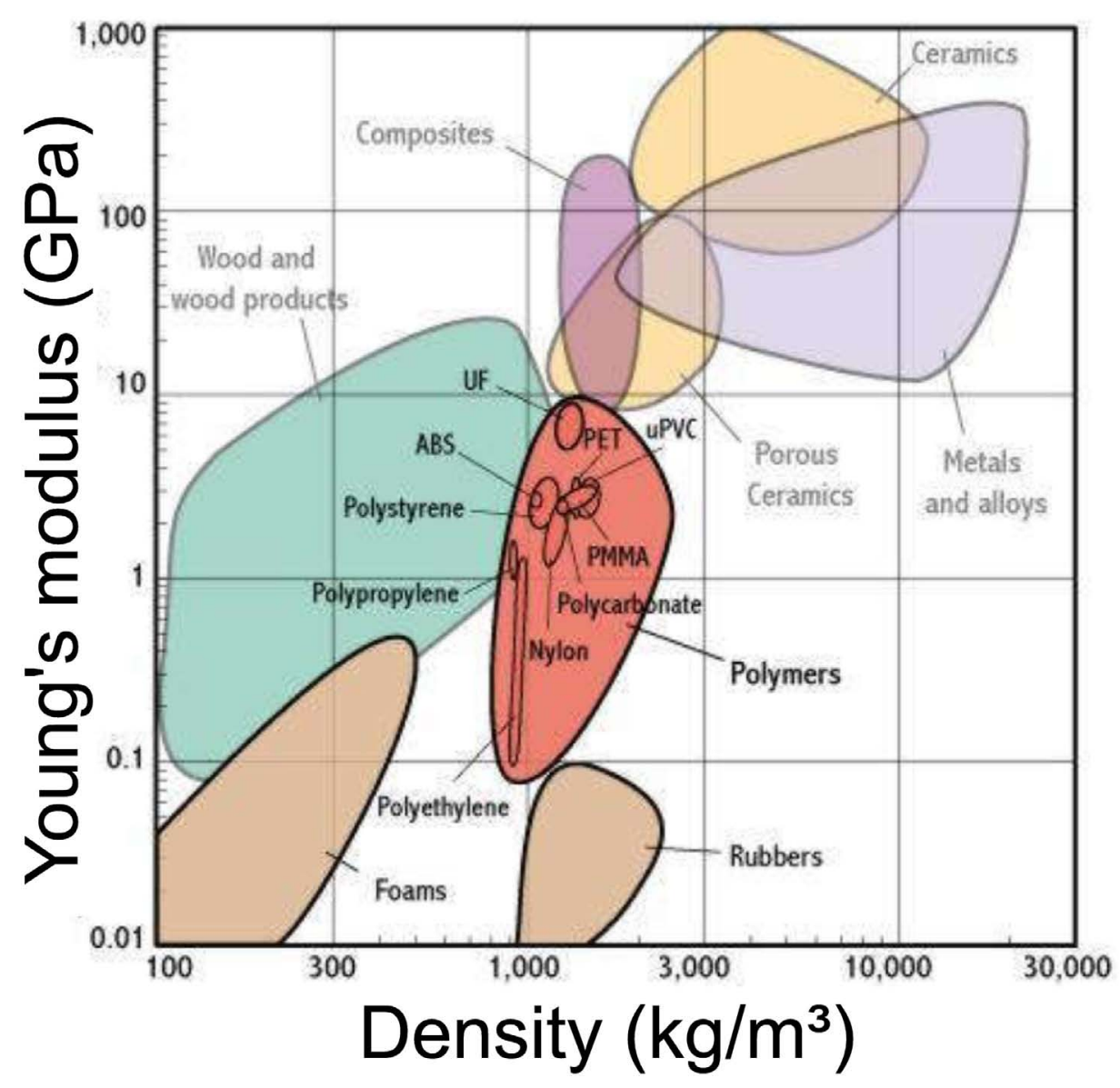

FIGURE 2 | The correlation between Young's modulus and density. Modified and permission granted by Lovatt et al. (2000).

the influence of this attachment method for a given sphere, we simulated the change in TS when a PMMA sphere is cut. The worst-case scenario that could reduce the TS would be if no adhesive is filled in the missing space caused by the cut. Figure 4 shows the influence of a cut on the TS of a sphere (diameter $8 \mathrm{~mm}$; cut width $0.8 \mathrm{~mm}$ ) compared with a solid sphere. When a sphere is cut, it is no longer omnidirectional. Thus, the TS value changes greatly with the direction from which the sphere is ensonified. The cut leads to a strong reduction in TS at $130 \mathrm{kHz}$ when the sphere is ensonified perpendicularly to the cut ( $x$-axis in Figure 4A). In the other directions, the effect is less pronounced and leads primarily to a shift in resonance peak compared with the solid sphere.

Using a 3D model led to long computation times, which were necessary in this case because the sphere is no longer rotationally symmetrical. Therefore, we simulated the frequency band only between 100 and $150 \mathrm{kHz}$. Several odontocetes fall in this spectrum, including harbor porpoises, which are an exemplary species throughout the manuscript.

\section{Air-Filled Spheres}

As reverberation caused by air bubbles is a widely known issue in sonar imaging, we simulated TS for air-filled spheres. To examine a realistic thickness that could resist pressure, spheres were between 5 and $60 \mathrm{~mm}$ in diameter with wall thickness between 1 and $28 \mathrm{~mm}$. Target strength of air-filled spheres is shown at $130 \mathrm{kHz}$ (Figure 5; additional figures in the Supplementary Information), the centroid frequency of a harbor porpoise. Compared with small $(<20 \mathrm{~mm}$ diameter) solid acrylic glass spheres (Figure 3), air-filled spheres made from acrylic glass do not perform better regarding TS values. For easier comparison, the relevant information of Figures 3, 5 are extracted and presented in Figure 6.

\section{Alternative Twine Materials}

Previous research has attempted to increase the detectability of gillnets by using new types of net materials, especially additives that increase the material density of the net filament. As these nets demonstrated little to no difference in TS measurements in the past (Larsen et al., 2007; Mooney et al., 2007), we simulated the TS of thin cylinders as a proxy for net filaments (Figure 7). The diameter of filaments of standard nets is typically $0.5 \mathrm{~mm}$ or thinner, and gillnets are rarely constructed from twine (which can consist of several filaments) thicker than $1 \mathrm{~mm}$. Overall, the TS is low across all densities and simulated diameters. A potentially relevant exception are cylinders with a very low 

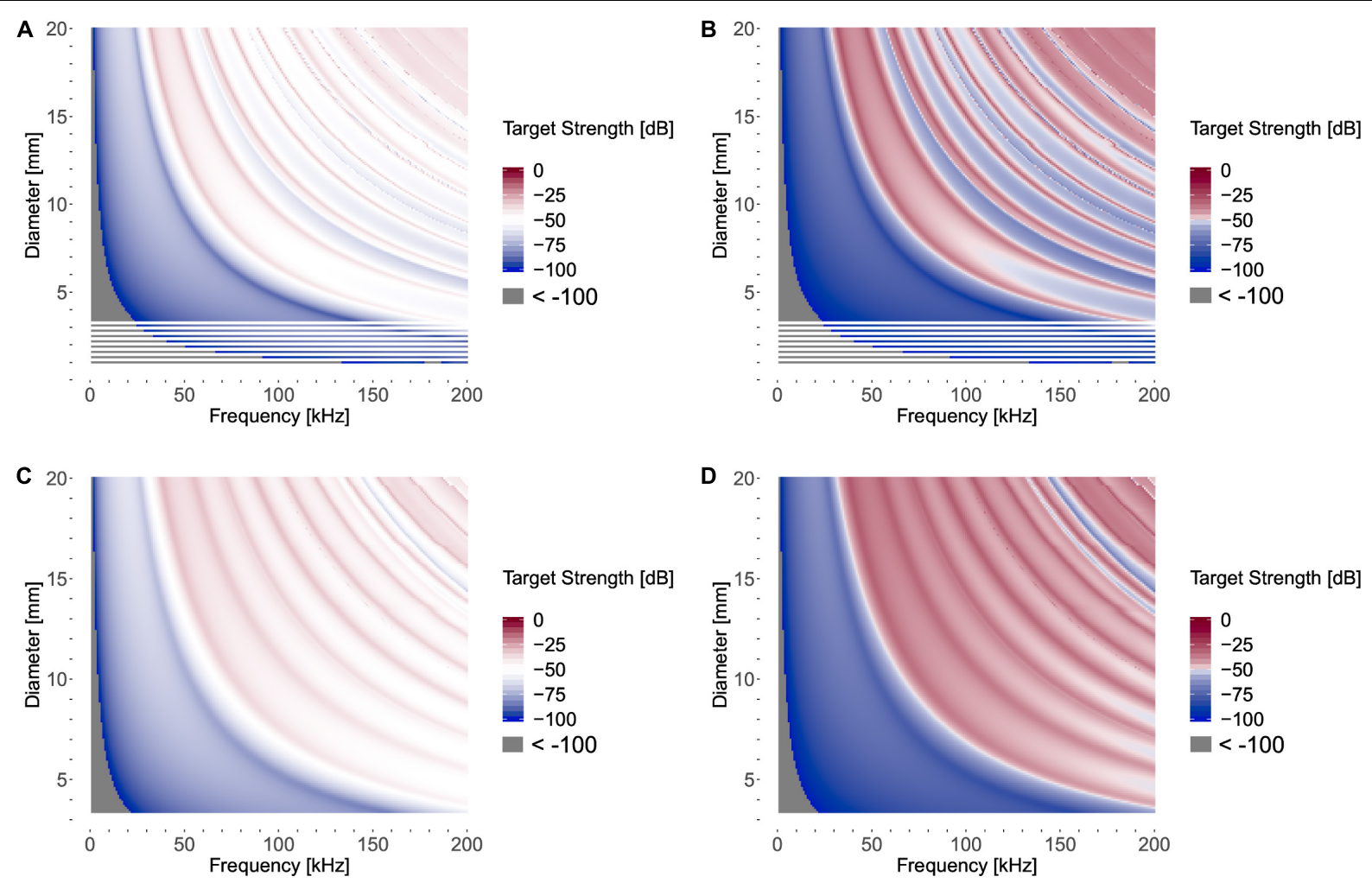

FIGURE 3 | Target strength of acrylic glass (PMMA) spheres at different diameters (increment $=0.1 \mathrm{~mm}$ ) across frequency spectrum (increment = $1 \mathrm{kHz}$ ) of echolocating odontocetes. (A,B) Young's modulus = 3.3 GPa, (C,D) Young's modulus = 4.8 GPa; At less than 3.4 mm, spheres have TS < -50 dB across all frequencies; gray area has TS values lower than $-100 \mathrm{~dB}$. Graphs are shown at two different color scales for illustration purposes. The raw data are given in Supplementary Information.
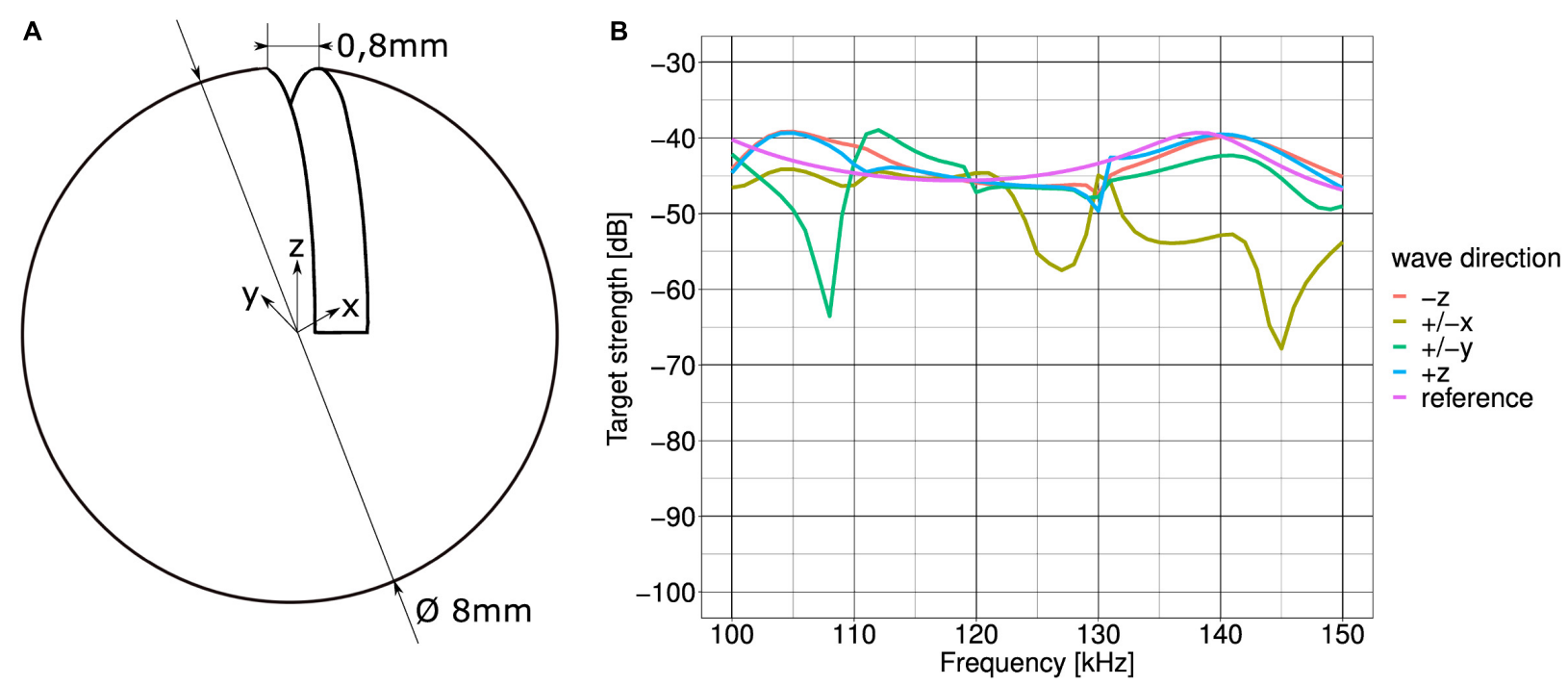

FIGURE 4 | (A) Drawing of a sphere with a cut; (B) TS of $8 \mathrm{~mm}$ acrylic glass (PMMA) sphere with a cut. Wave direction is the direction of the propagating sound corresponding to the arrows in (A); "reference" is a solid sphere of $8 \mathrm{~mm}$.

elasticity (Young's modulus), i.e., $0.1 \mathrm{GPa}$ (Figure 7, undermost row in all graphs). Materials with this Young's modulus belong to the material class rubber (Figure 2). Additionally, few parameter combinations also resulted in relatively high TS; for instance, the highest TS value is achieved at $120 \mathrm{kHz}$, at a material density of $4000 \mathrm{~kg} / \mathrm{m}^{3}$, diameter of $1.75 \mathrm{~mm}$, and a Young's modulus 


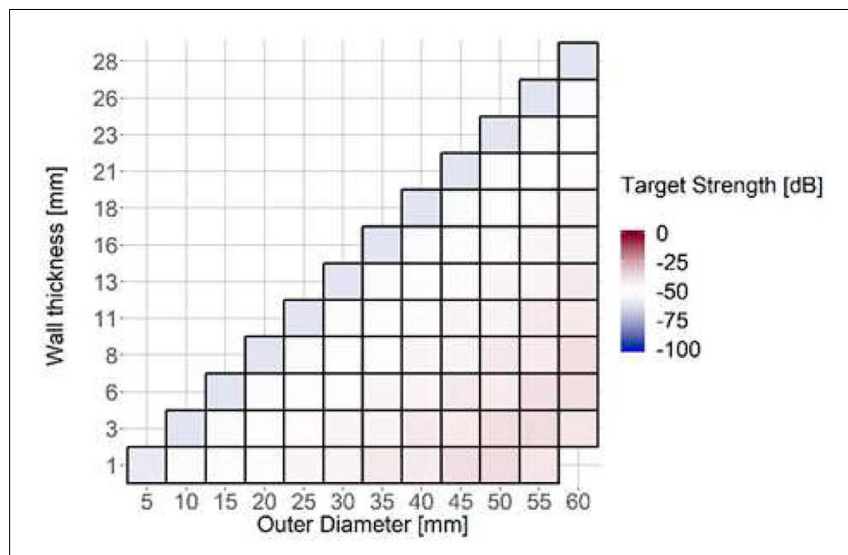

FIGURE 5 | Target strength of hollow spheres made from acrylic glass (PMMA), exemplarily at $130 \mathrm{kHz}$. use several signal types, we noted the frequency used for foraging. Figure $\mathbf{8}$ shows the values for TS vs. diameter for harbor porpoises.

\section{Verification of Selected Simulation Results}

We experimentally verified the TS simulation results for selected spheres using a sweep signal in an acoustic tank. Figure 9 shows measurements of the two selected acrylic glass sphere sizes, both experimental and simulated data. Target strength was simulated for the standard literature value for Young's modulus of PMMA (3.3 GPa) as well as for the value adapted to high frequencies $(4.8 \mathrm{GPa})$. For comparison, we also measured the TS of two reference objects, i.e., a TT ball (essentially air) and a steel sphere (high density, high Young's modulus = low elasticity; Figure 10). For some frequencies, the PMMA spheres perform almost as well as the larger objects.

of $1.1 \mathrm{GPa}$ (not shown in Figure 7). However, such a material currently does not exist because Young's modulus is positively correlated with density (Figure 2).

\section{Identification of Optimal Spheres for Selected Odontocete Species}

Many odontocete species are taken as bycatch (Reeves et al., 2013). For the 10 species most frequently taken as bycatch, as well as the species taken as bycatch that are classified as "Critically Endangered" or "Endangered" according to the IUCN Red List (IUCN, 2019), we calculated the acrylic glass sphere size with the highest TS depending on the centroid frequency of their echolocation signals (Table 2). Because the ideal spheres would be small, we extracted the optimal sphere sizes less than $20 \mathrm{~mm}$ diameter, as well as less than $10 \mathrm{~mm}$ diameter from Figure 3. We used $-50 \mathrm{~dB}$ as a threshold and marked spheres with a lower TS in bold. The TS values were extracted for the closest frequency-bin (1$\mathrm{kHz}$ increment). For some species, especially delphinids, who

\section{Sonar Imaging of Standard and Modified Net}

The addition of acrylic glass spheres aims to (a) increase the TS of the gillnet to increase the detection distance of the nets for odontocetes, and (b) change the acoustic image so that it is perceived as an obstacle. To qualitatively confirm that the addition of acrylic glass spheres will substantially increase the echo of a gillnet and alter its acoustic image, a prototype net was built (Supplementary Figure 6) and sonar images were taken by ensonifying both a standard and a modified net with a $38 \mathrm{kHz}$ and a $120 \mathrm{kHz}$ sonar aboard RV Clupea. Both nets were subsequently placed underneath the vessel. Figure 11 shows the echograms taken. At $38 \mathrm{kHz}$, both standard and modified nets show only the floatline and leadline, whereas at $120 \mathrm{kHz}$, the attached spheres are almost as visible as the floatline. For comparison, Supplementary Figure 7 shows typical pillar shaped schools of sprat (Sprattus sprattus) taken on RV Solea (SIMRAD EK80, $120 \mathrm{kHz}$ ).

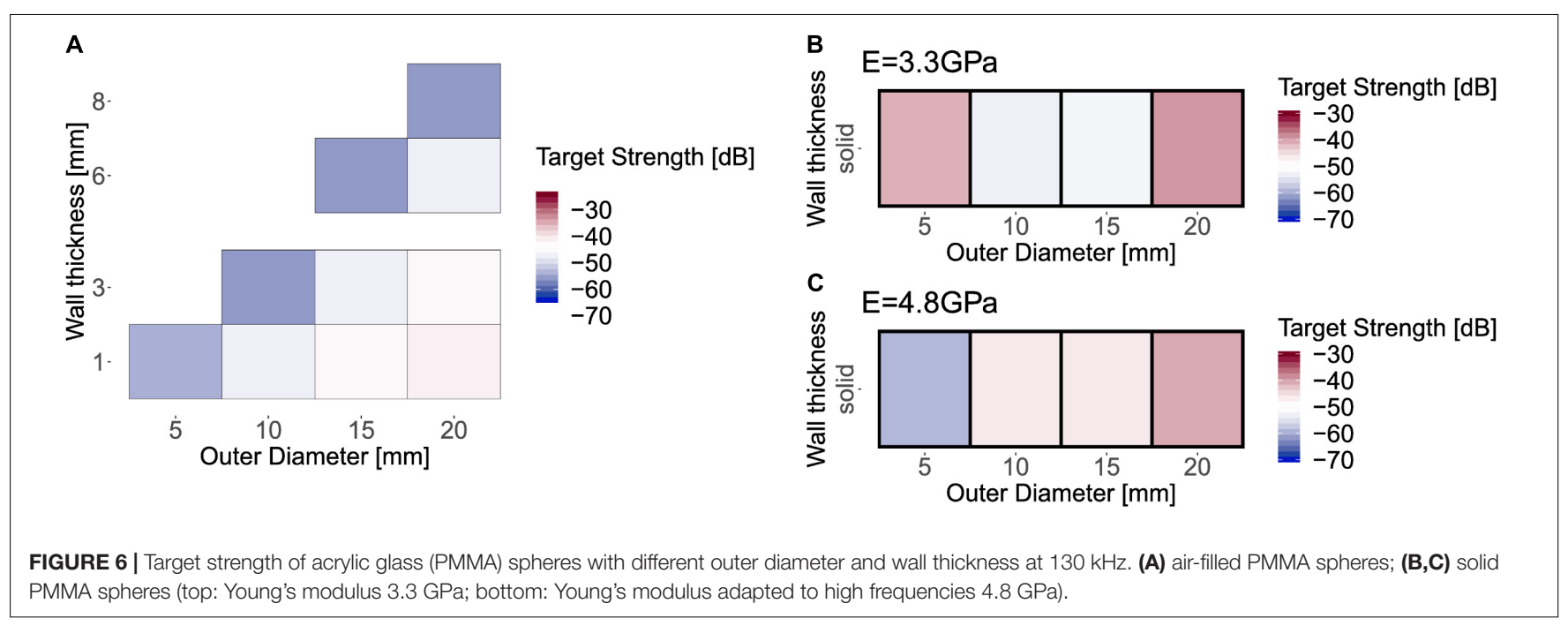



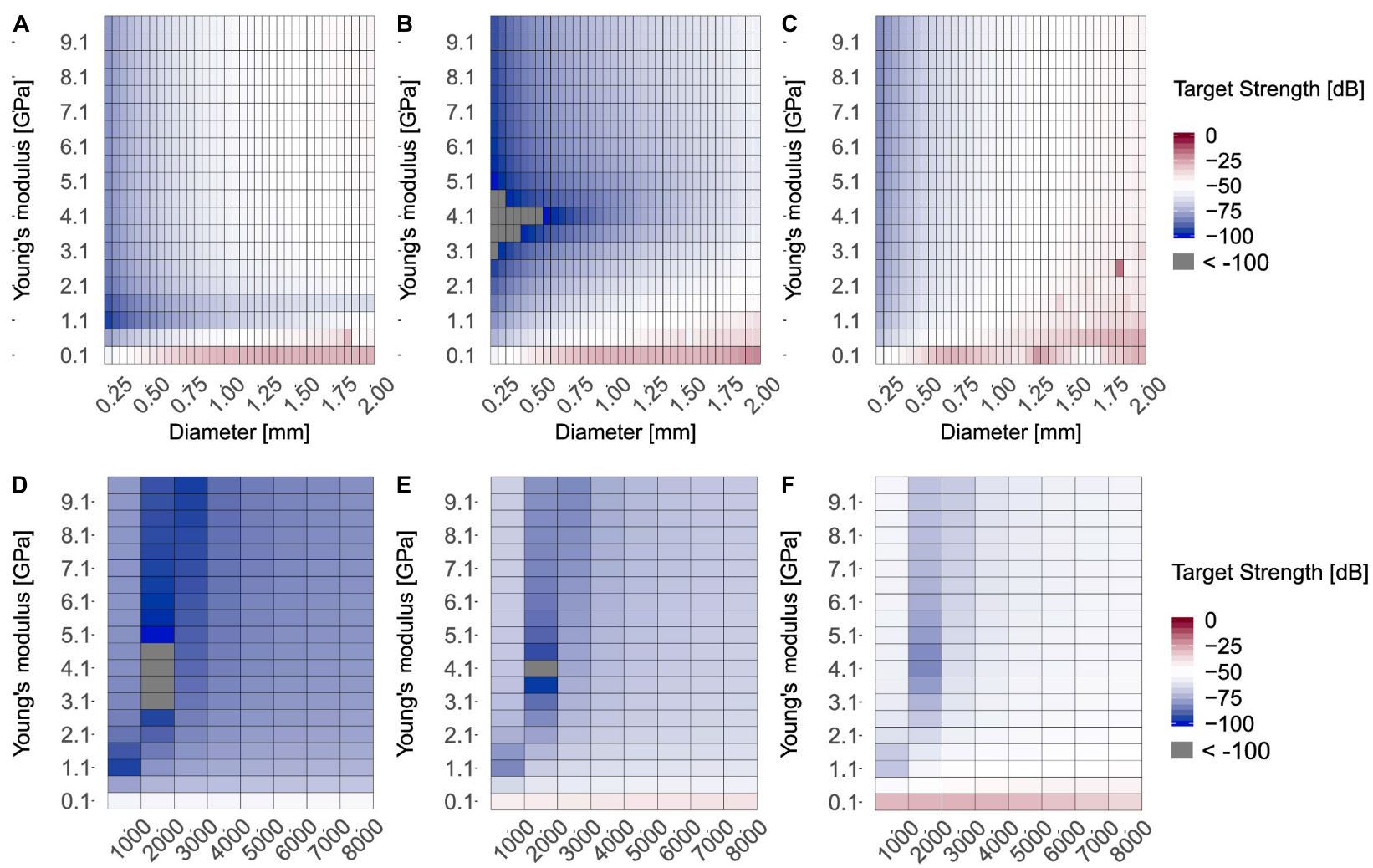

Density $\left[\mathrm{kg} / \mathrm{m}^{3}\right]$

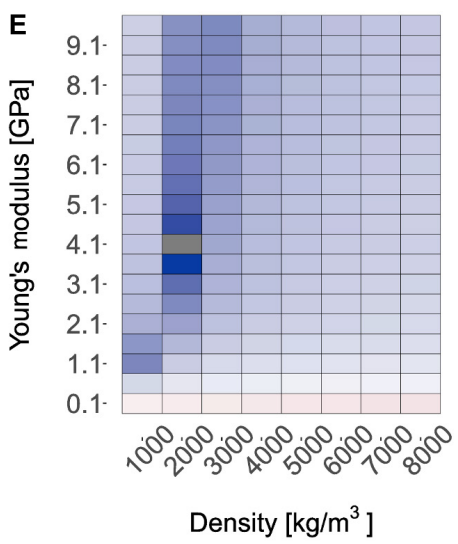

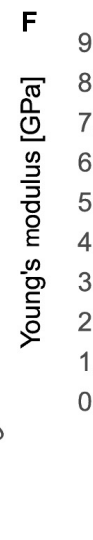

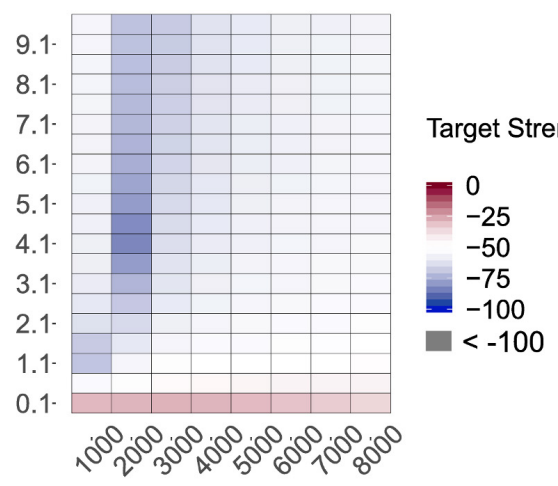

Density $\left[\mathrm{kg} / \mathrm{m}^{3}\right]$

FIGURE 7 | (A) Target strength of solid cylinders at $\rho=1000 \mathrm{~kg} / \mathrm{m}^{3}$; (B) $\rho=2000 \mathrm{~kg} / \mathrm{m}^{3}$; and (C) $\rho=8000 \mathrm{~kg} / \mathrm{m}^{3}$ at $130 \mathrm{kHz}$. Each cell represents one simulation; colors range from strong echo (red) to low echo (blue). (D-F) Show the interaction between material density and elasticity for three cylinder diameters: (D) $0.25 \mathrm{~mm}$, (E) $0.5 \mathrm{~mm}$, (F) $1 \mathrm{~mm}$. Additional frequencies and material densities are available in Supplementary Information.

TABLE 2 | Optimal sphere sizes of acrylic glass (PMMA) spheres to increase the reflectivity of gillnets for different odontocete species.

\begin{tabular}{|c|c|c|c|c|}
\hline Species & $\begin{array}{l}\text { Centroid frequency } \\
{[\mathrm{kHz}]}\end{array}$ & $\begin{array}{c}\text { Sphere size } \\
{[\mathrm{mm}] \leq 20 \mathrm{~mm}} \\
\text { (TS }[\mathrm{dB}])\end{array}$ & $\begin{array}{c}\text { Sphere size } \\
{[\mathrm{mm}] \leq 10 \mathrm{~mm}(\mathrm{TS}[\mathrm{dB}])}\end{array}$ & $\begin{array}{l}\text { Reference for } \\
\text { frequency }\end{array}$ \\
\hline Lissodelphis borealis & 18.2 & $20(-61.68)$ & $10(-75.65)$ & Rankin et al., 2007 \\
\hline Delphinus delphis & 112 & $18.6(-31.36)$ & $9.9(-37.43)$ & Morisaka and Connor, 2007 \\
\hline Phocoena phocoena & 130 & $18.5(-32.08)$ & $8.5(-38.78)$ & Villadsgaard et al., 2007 \\
\hline Lagenorhynchus obliquidens & 94.6 & $18.5(-31.08)$ & $8.1(-37.78)$ & Morisaka and Connor, 2007 \\
\hline Phocoenoides dalli & 133 & $18.1(-32.22)$ & $8.3(-38.97)$ & Morisaka and Connor, 2007 \\
\hline Neophocaena phocaenoides & 125 & $19.2(-32.03)$ & $8.9(-38.47)$ & Morisaka and Connor, 2007 \\
\hline Stenella coeruleoalba & 40 & $19.1(-30.26)$ & $10(-67.60)$ & Kastelein et al., 2003 \\
\hline Pontoporia blainvillei & 130 & $18.5(-32.08)$ & $8.5(-38.78)$ & Morisaka and Connor, 2007 \\
\hline Tursiops truncatus ponticus & 80 & $18(-33.38)$ & $9.6(-36.28)$ & Wahlberg et al., 2011 \\
\hline Lagenorhynchus obscurus & 73.8 & $19.5(-32.73)$ & $10(-38.04)$ & Morisaka and Connor, 2007 \\
\hline Phocoena sinus & 132 & $18.2(-32.54)$ & $8.4(-38.86)$ & Morisaka and Connor, 2007 \\
\hline Phocoena phocoena relicta & presumably 130 & $18.5(-32.08)$ & $8.5(-38.78)$ & \\
\hline Platanista gangetica & 64.4 & $17(-32.72)$ & $10(-53.14)$ & Jensen et al., 2013 \\
\hline Orcaella brevirostris & 94.6 & $18.5(-31.08)$ & $8.1(-37.78)$ & Jensen et al., 2013 \\
\hline Inia geoffrensis geoffrensis & 101.2 & $17.2(-31.85)$ & $7.5(-38.38)$ & Ladegaard et al., 2015 \\
\hline Cephalorhynchus hectori & 124 & $19.4(-31.61)$ & $8.9(-38.41)$ & Thorpe and Dawson, 1991 \\
\hline
\end{tabular}

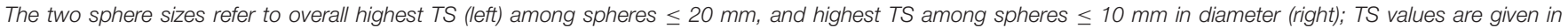

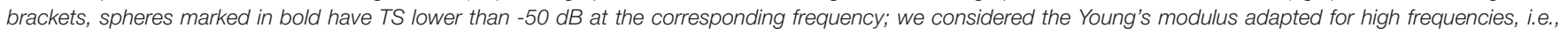
$4.8 \mathrm{GPa}$; the optimal sphere sizes for other frequencies can be extracted from raw data underlying Figure 3, which are given in Supplementary Information. 
TABLE 3 | Comparison of TS for different types of gillnets with and without additives in the netting material; 10 , iron oxide in nylon filaments; BaSO 4 , Barium Sulfate in nylon filaments.

\begin{tabular}{|c|c|c|c|c|}
\hline Diameter [mm] & Frequency [kHz] & Net material & TS [dB] & References \\
\hline 0.59 & 130 & Nylon netting & -53 & Larsen et al., 2007 \\
\hline 0.59 & 130 & Nylon netting + 10 & -53 & Larsen et al., 2007 \\
\hline 0.65 & 130 & Nylon netting & -48.5 & Kastelein et al., 2000 \\
\hline 0.5 & 230 & Nylon filament & -61 & Pence, 1986 \\
\hline 0.51 & 120 & Nylon netting & -52 & Mooney et al., 2004 \\
\hline 0.51 & 120 & Nylon netting $+\mathrm{BaSO}_{4}$ & -53 & Mooney et al., 2004 \\
\hline 0.49 & 120 & Nylon netting & -58.8 & Au and Jones, 1991 \\
\hline
\end{tabular}
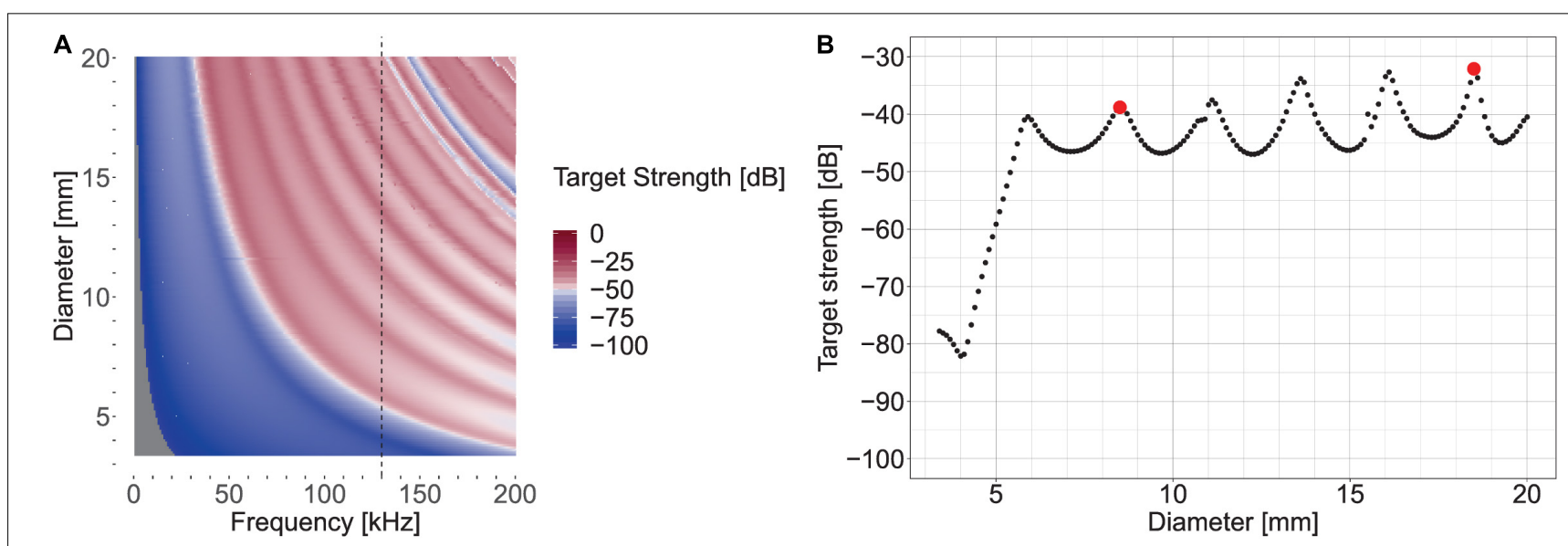

FIGURE 8 | (A) Figure 3, all simulated frequencies, diameters and corresponding TS for acrylic glass spheres (Young's modulus 4.8 GPa for high frequencies); straight line indicates frequency of harbor porpoise (P. phocoena); (B) TS values for different diameters at $130 \mathrm{kHz}$ (frequency of $P$. phocoena); red dots mark maximum noted in Table 2; other odontocete frequencies are available in the Supplementary Information.

\section{Effect on Potential Detection Distances}

In addition to altering the perceived image of the gillnet, it is essential that the net be detected as early as possible, allowing the animal to react in time to avoid the obstacle. For some species, target detection experiments have been conducted, and detection ranges for various targets estimated (Au et al., 2007). We exemplify the effect of adding objects with strong echo properties on the potential detection distances for harbor porpoises by modeling the potential detection distances for $8 \mathrm{~mm}$ acrylic glass spheres in several modification options, i.e., different numbers of spheres per area netting (Figure 12). The overall TS depends on how many spheres are ensonified simultaneously, which is related to the number of spheres per net area as well as the direction from which the animal is approaching the net. If the animal is swimming perpendicularly $\left(0^{\circ}\right.$ angle) to the net, it will most likely ensonify more spheres simultaneously than when it swims at an angle. At angles, echoes from different spheres are received by the animal at subsequent points in time owing to runtime differences. Extinction effects may occur when the reflected waves interfere with each other as a result of phase shifts. Therefore, we calculated both the maximum detection range (coherent addition of TS) and the most likely mean detection range (incoherent addition). Incoherent addition statistically accounts for TS-reducing factors, such as angle of incident or distance between emitter and receiver (in this case, the emitter is the melon, and the receiver is the jaw of the odontocete). The calculated TS of net area covered with additional spheres determines the detection range. To compare the detection range with previous experimental data, we used an ensonified area of $0.36 \mathrm{~m}^{2}$. The equal detection range of spheres either 0.5 or $0.6 \mathrm{~m}$ apart is the result of the distribution within the circular area. When a standard gillnet is equipped with spheres approximately $0.3 \mathrm{~m}$ apart, an ensonified area of $0.36 \mathrm{~m}^{2}$ should be visible from at least $12 \mathrm{~m}$ and could be visible up to $17 \mathrm{~m}$, which is as far as $0.68 \mathrm{~m}$ of floatline. This in turn means that, if harbor porpoises are able to detect the equivalent TS of a floatline, the entire netting area should appear as strong as the floatline as well. If spheres were attached at a much smaller distance, the detection distance of an area of $0.36 \mathrm{~m}^{2}$ could increase up to $40 \mathrm{~m}$. Regardless of whether one or more spheres are ensonified, the spheres outcompete all netting materials that have been considered previously.

\section{DISCUSSION}

Creating sustainable ways to reduce species loss while maintaining provisional ecosystem services can be a challenge. Previous work to reduce the bycatch of toothed whales (odontocetes) includes time and area closures (Murray et al., 


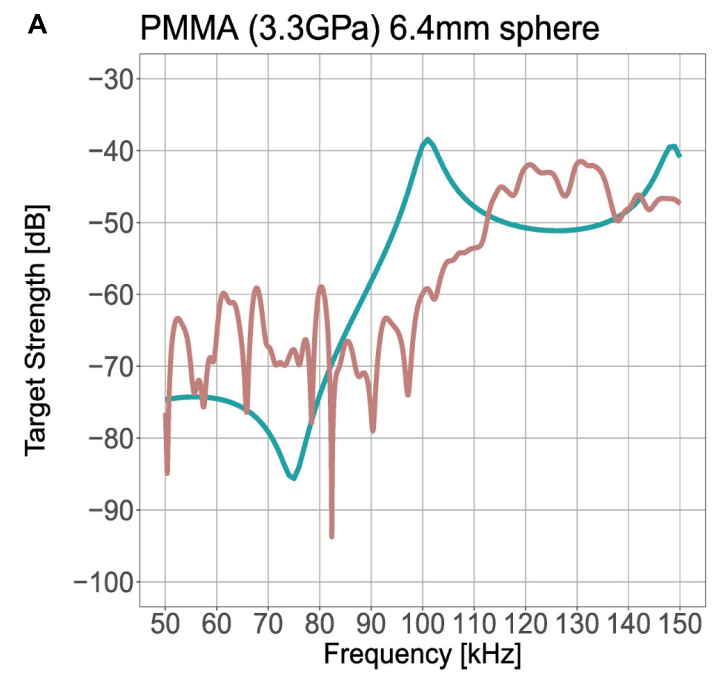

C

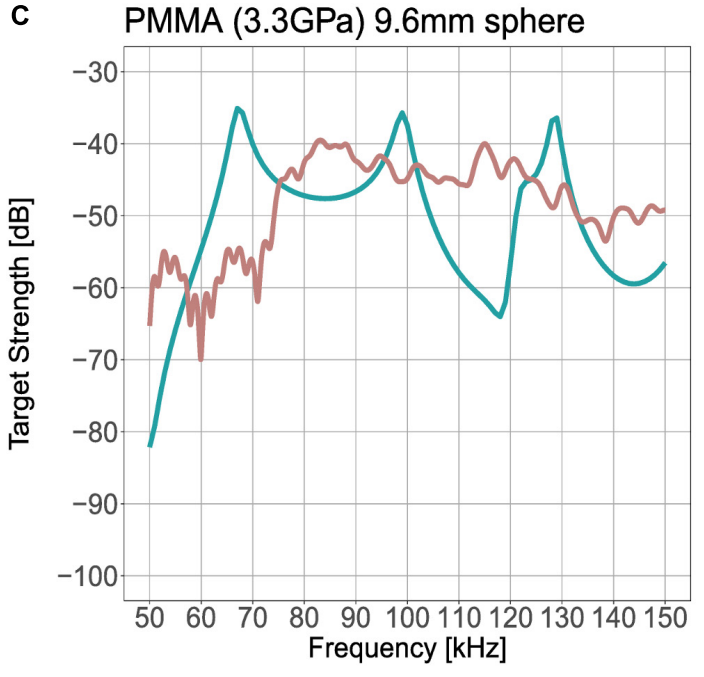

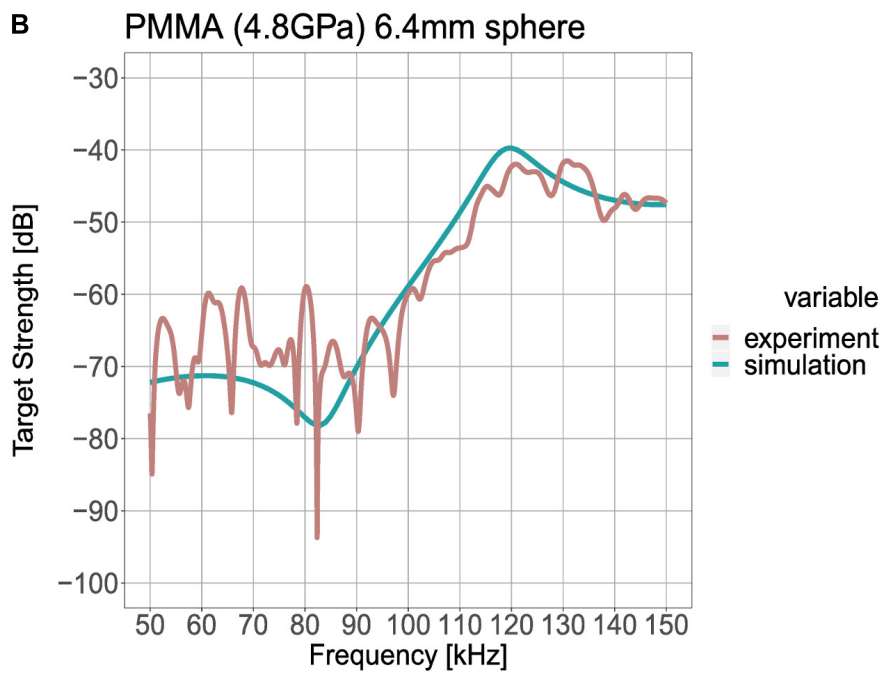

D

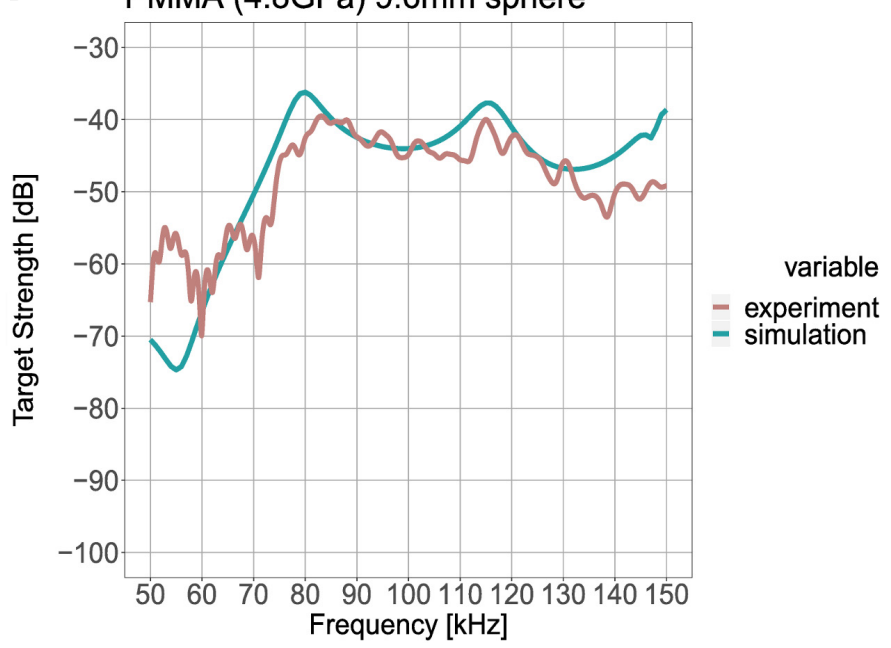

FIGURE 9 | Comparison of experimental and simulated TS of two different acrylic glass (PMMA) spheres. Left (A,C): simulation with a standard value for Young's modulus at 3.3 GPa; right (B,D): Young's modulus adapted to high frequencies (4.8 GPa)

2000; Gormley et al., 2012), the use of acoustic deterrent devices (pingers), and experiments with supposedly acoustically enhanced nets (Kraus et al., 1997; Larsen et al., 2007; Bordino et al., 2013; Dawson et al., 2013; Mangel et al., 2013; Larsen and Eigaard, 2014). The drawbacks of pingers over passive reflectors include potential habituation (Cox et al., 2001), potential exclusion from habitat (Carlström et al., 2009), higher bycatch rates if a subset of pingers fail (Carretta and Barlow, 2011), and a possible "dinner-bell" effect for other species (Bordino et al., 2002). So far, studies of acoustically enhanced nets have produced inconclusive results.

One major issue is the trial-and-error-approach to select gillnet modification for acoustical "enhancement" of gillnets without an understanding of the fundamental acoustic properties of such modifications.

Here, in order to expand the portfolio of technical measures to reduce bycatch of toothed whales, we systematically explored the acoustic properties of a wide range of gillnet filaments, as well as a range of objects that could be added to gillnets to enhance their acoustic detectability. We identified species-specific resonators that might increase the TS of gillnets and thus potentially increase the detection distance for odontocetes. The modifications might not only let odontocetes detect gillnets earlier, but also make the gillnets appear as objects they cannot swim through, if mounted properly.

In a first step, we identified the requirements for potential modifications: The object has to be (a) omnidirectional, (b) small, and (c) neutrally buoyant in order to avoid changes to the behavior of the net. Similar requirements for passive acoustic reflectors were also identified by Goodson (1997). As spheres meet the demand of omnidirectionality, we concentrated on simulating spherical targets. Spheres are also used as standard targets in many sonar applications (MacLennan, 1981; Foote, 1982, 1983; Sheng and Hay, 1993; Atkins et al., 2008). In his consideration of spherical acoustic targets as passive reflectors to decrease bycatch of odontocetes, Goodson (1997) remarks 


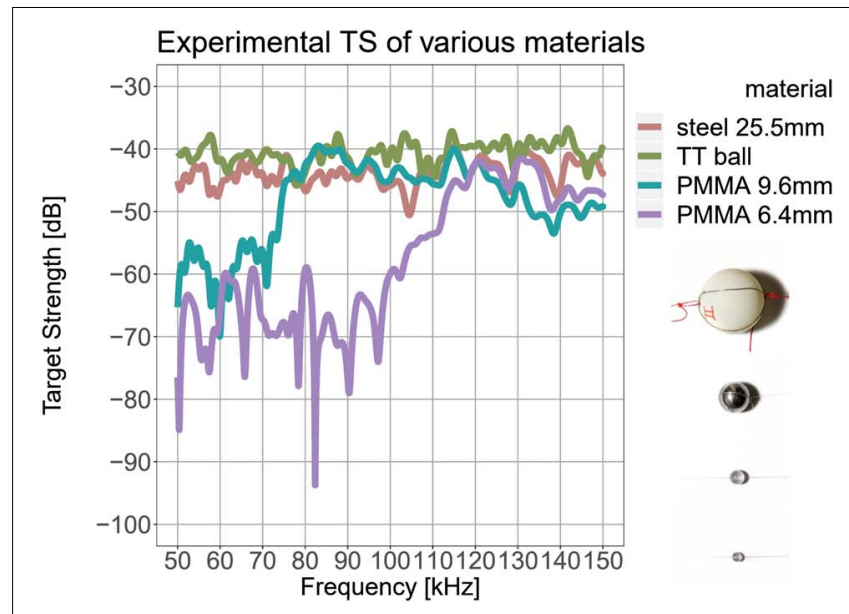

FIGURE 10 | Experimental TS measurements for different objects, including steel sphere, a table-tennis ball ( $\Pi \mathrm{T}$ ball) and two acrylic glass (PMMA) spheres of different sizes; objects are shown underneath legend.

that, as a consequence of Rayleigh scattering, any sphere as a passive reflector would have to be several centimeters in size. Similarly, other potential shapes for acoustic targets such as radar reflectors, which could very well channel the incoming sound waves and reflect them back to the source, would have to be larger, because they operate on geometrical reflectivity (Perrin et al., 1994). These considerations do not consider the potential use of resonance effects. Resonance effects can occur when using objects with greater elasticity (lower Young's modulus) than rigid objects. A non-rigid object can exhibit resonance effects when ensonified with its natural frequency (eigenfrequency); the sphere will oscillate and move the surrounding medium (Sullivan-Silva, 1989). These resonating properties depend largely on elasticity (Sheng and Hay, 1993). The identification of the optimal elasticity in relation to size led to the conclusion that several polymers could be suitable material. We chose acrylic glass as a suitable material, as it best matched the simulated parameters and has further advantages for the application in fisheries, such as:

(a) density close to seawater $\left(1180 \mathrm{~kg} / \mathrm{m}^{3}\right.$, Abts, 2016) making it almost neutrally buoyant and thus less likely to change net behavior;

(b) high transparency in water, which could make it less visible to fish;

(c) low melting temperature compared with nylon, resulting in potential attachment techniques that allow the acrylic glass to be molded directly onto the net, because many nets are made of nylon;

(d) low water absorption coefficient, thus the acoustic properties should stay constant throughout the entire soak time of the gillnet;

(e) wide availability;

(f) manufacture possible in all sizes;

(g) can be glued using liquid acrylic glass adhesive.

Figures 1, 2 show that other polymer materials could also be used as acoustic targets, but are not considered further in this work. Therefore, the acoustic properties of targets made of these materials need further investigation.

Air-filled spheres did not outperform solid spheres made of PMMA. This may be because the TS is not determined by the air inside the spheres, but mostly by the properties of the shell material (Welsby and Hudson, 1972).

Some early work has been done on passive reflectors, which resulted in promising objects that may have been clearly acoustically visible to odontocetes, but failed to meet the requirement of being easy to handle (Hembree and Harwood, 1987; Peddemors et al., 1991). The acrylic glass spheres described here are not only made from a polymer that inherently eliminates the issue of rusting as described in Peddemors et al. (1991), but they are also small enough to avoid the necessity for additional storage space for the nets.

We have identified optimal sphere sizes for odontocetes species that are commonly taken as bycatch or listed as vulnerable (Table 2). For all species with echolocating frequencies above $40 \mathrm{kHz}$, spheres smaller than $20 \mathrm{~mm}$ in diameter were identified with TS $>-50 \mathrm{~dB}$. For most of these species, spheres smaller than $10 \mathrm{~mm}$ were identified, as well. The threshold of $-50 \mathrm{~dB}$ that was used is approximately the TS of a gillnet (Au and Jones, 1991; Perrin et al., 1994; Kastelein et al., 2000; Mooney et al., 2004). This threshold is lower than the threshold suggested by Goodson (1997). However, he considered larger spacing between objects to be attached to gillnets to avoid the need for additional space on small boats. The smaller the spheres, the more additional objects could be attached to gillnets without impeding usability.

In this study, we attached the spheres to the gillnet by cutting them in half and gluing them to the net filament using fluid acrylic glass adhesive. The simulation results reveal that a small cut in the sphere can potentially lead to a drop in TS at the desired frequencies. This effect is more pronounced if the odontocete echolocates from a certain direction. In practice, however, this is counteracted by filling the cut with an acrylic glass adhesive. Further compensation of potential reduction in TS at different directions is achieved through random orientation of the spheres at the net and movement of the gillnet underwater.

The experimental verification of the TS calculations for acrylic glass indicated that the measurements in the tank are in good agreement with the modeled data, when the Young's modulus (material elasticity) is adapted from literature values of approximately 3.3-4.8 GPa. One reason for the change in Young's modulus could be that the TS measurements were taken at high frequencies, whereas the Young's modulus is usually determined at quasi-static conditions, usually in tensile testing. However, the Young's modulus of polymers changes when exposed to high frequencies (Pritz, 1994; Dauchez et al., 2002), thus, the exposure to high frequency acoustic waves is more comparable to dynamic testing of the Young's modulus. The dynamic Young's modulus is slightly higher than the static Young's modulus (Sabbagh et al., 2002; Popov and Sabev, 2016). The TT ball used as a reference target had a similar TS as previous measurements of this target (Welsby and Hudson, 1972).

In addition to the attachment of additional objects to enhance the acoustic visibility of gillnets, a common approach so far has been to increase the density of the gillnet filament itself. 
A

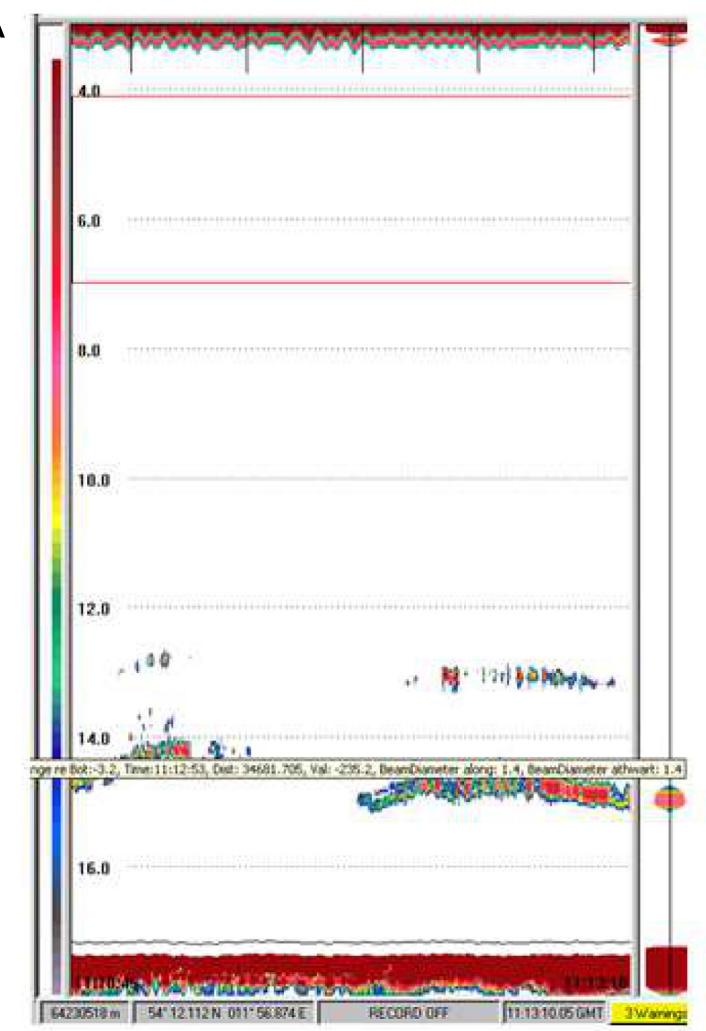

C

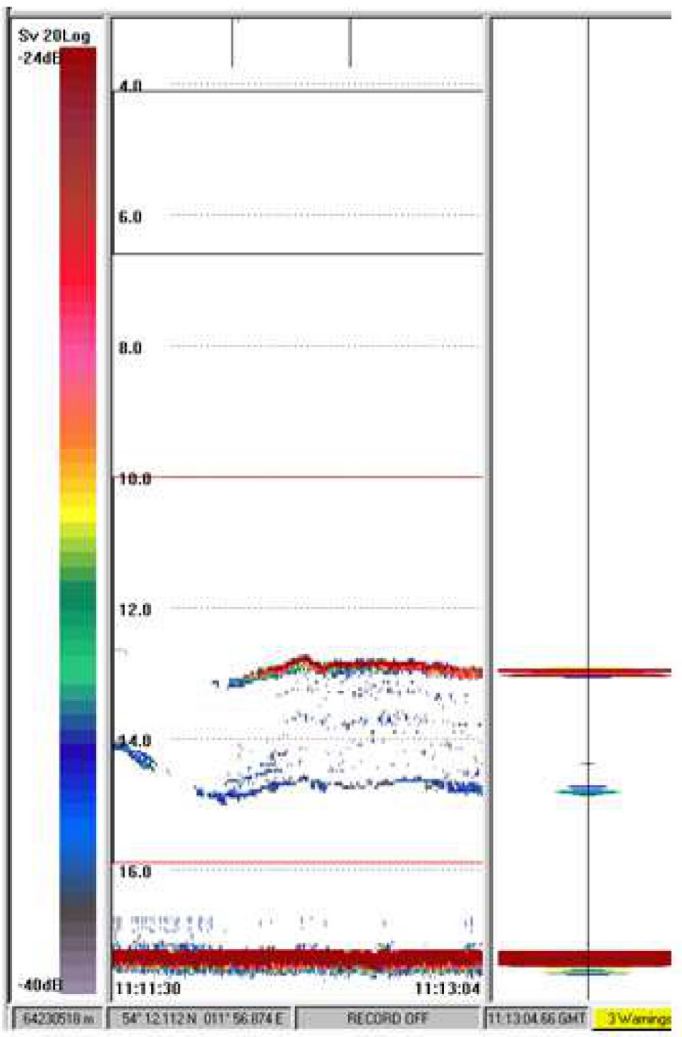

B
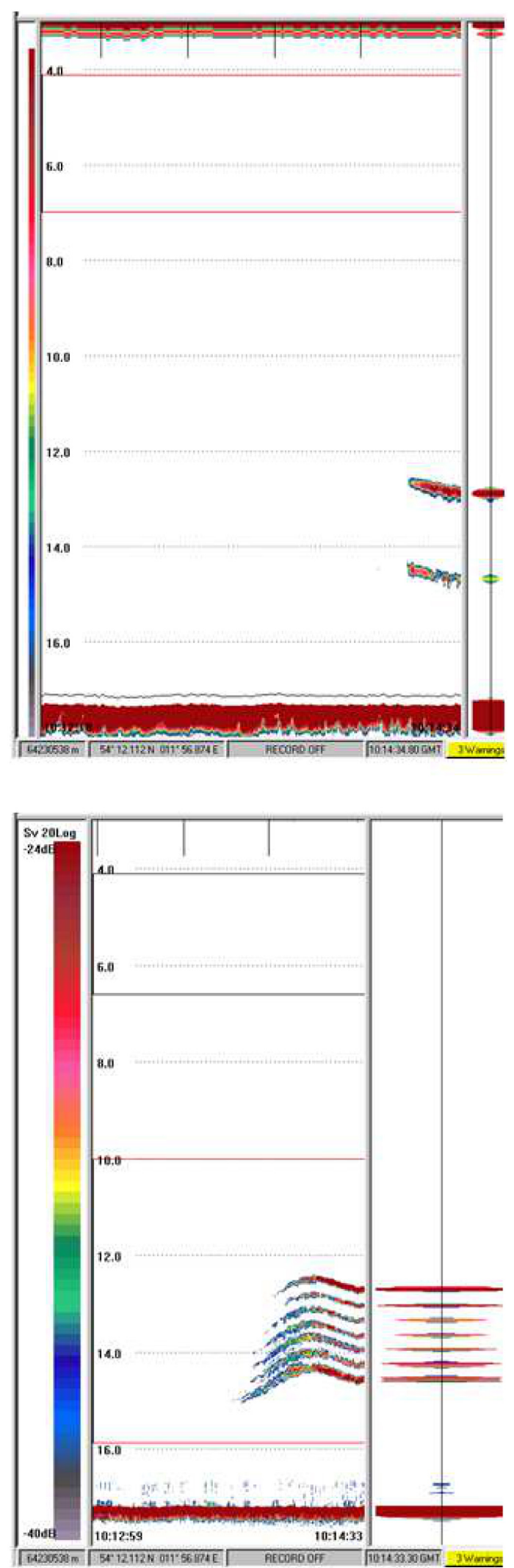

FIGURE 11 | Left: (A,C) echograms of standard gillnet; right: (B,D) modified gillnet at $38 \mathrm{kHz}$ (upper: A,B), and at $120 \mathrm{kHz}$ (lower: C,D). The added spheres are clearly visible at $120 \mathrm{kHz}(\mathbf{D})$, but not at $38 \mathrm{kHz}(\mathbf{B})$, whereas the standard gillnet is hardly visible, independent of the frequency. 

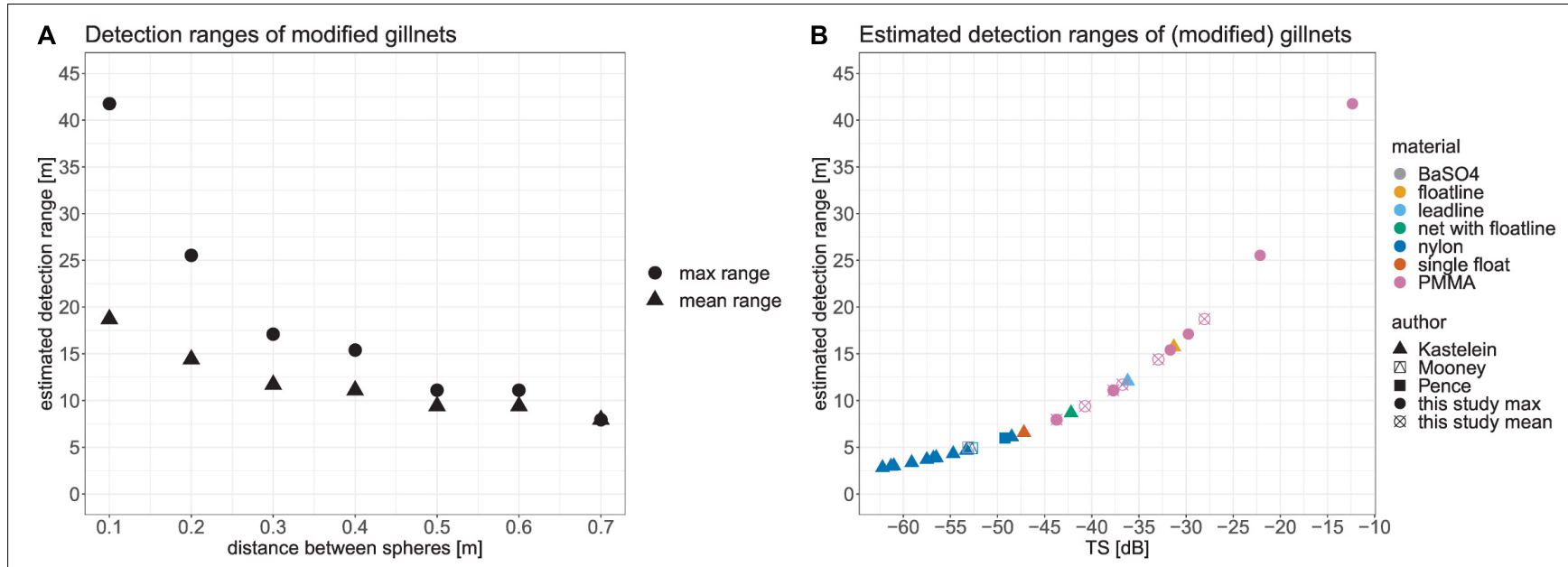

FIGURE 12 | Estimates of potential detection ranges for harbor porpoises. (A) Maximum and mean estimated detection ranges for gillnets equipped with $8 \mathrm{~mm}$ acrylic glass (PMMA) spheres in an ensonified area $0.36 \mathrm{~m}^{2}$ at different distances between spheres. (B) comparison of gillnets with $8 \mathrm{~mm}$ spheres at different distances (open circle $=$ mean, filled circle $=$ maximum) to ranges determined from literature values (Pence, 1986; Kastelein et al., 2000; Mooney et al., 2004). Colors encode the material/object, and shapes encode the source of information.

Therefore, we have investigated the acoustic properties of a wide range of thin cylinders, as a proxy for gillnet filaments.

In general, the TS of thin, infinite cylinders (or filaments), irrespective of material properties, was very low. The calculated results presented here are similar to the theoretical values calculated by Pence (1986). The TS hardly differs between material densities within a given diameter of the cylinder, especially when density differences are small. In previous studies of gillnets with added $\mathrm{BaSO} 4$ and iron oxide (IO), the material density was increased by only 8 and $11 \%$, respectively (Mooney et al., 2004; Larsen et al., 2007). Target-strength measurements of such acoustically enhanced gillnets are in line with the simulation results, because they do not reveal a significant difference between standard and modified gillnets (Table 3). One reason for the small difference in TS is that there is a geometric - and mass - threshold of the target object that needs to be exceeded in order to initiate an interaction between object and sound wave. Therefore, Goodson (1997) did not regard denser netting materials as an option. The TS of several meshes of netting is, in the best case, equivalent to the TS of a single $8 \mathrm{~mm}$ acrylic glass sphere. Thin cylinders with a diameter of $0.5 \mathrm{~mm}$, material density of $2000 \mathrm{~kg} / \mathrm{m}^{3}$, and Young's modulus of $4.1 \mathrm{GPa}$ at $130 \mathrm{kHz}$ have very low TS values. These material properties are close to the properties of nylon, which could explain the very low TS values of monofilament gillnets and thus their poor acoustic visibility. Nevertheless, these results need further experimental verification. Because the TS of gillnet netting cannot be substantially increased by increasing the density of the net material itself, any further trials in this direction will most likely be in vain.

The only way to obtain high TS of thin cylinders is through the use of a cylinder with very low Young's modulus, i.e., rubber material (Figures 2, 7). The strength of standard rubber material is too low to be used as netting material, an option could be to attach rubber strings to the net. The drawback of using a cylindrical shape is the loss of omnidirectionality.
Additionally, we lack the information about a minimum length of such additional rubber filaments to be effective as acoustic targets. In case this modification is considered in future studies, further exploration would be needed to determine the minimum cylinder length via modeling and subsequently verify these results in an acoustic tank.

\section{Detection Distances/Ecological Significance}

In a parametric study, we have simulated a large number of different objects to identify the ideal objects that might allow odontocetes to perceive gillnets early on and classify them as an obstacle. We simulated a wide range of frequencies to cover many odontocete species and allow us to identify optimal objects for different species, and so ensure a wide application of the modification.

The main reason for odontocete bycatch in gillnets is assumed to be the faint echo of gillnet netting, which is not recognized as an obstacle (Goodson, 1997). Although, odontocetes are most likely able to detect parts of gillnets, such as floatlines, from a distance (Nielsen et al., 2012), they are taken as bycatch in gillnets.

Therefore, the overall goal of this study was to identify passive reflectors that substantially improve the acoustical visibility of gillnets within the frequency range of echolocating odontocetes. This is the basis to increase the potential detection distance of gillnets and alter the acoustic image of the gillnet to be recognized as an obstacle by odontocetes.

Because gillnets' floatline has a much higher TS than the netting itself, the received echo of floatline and netting may not be perceived as an obstacle. It is known that harbor porpoises and Dall's porpoises are more likely to swim underneath rather than over an obstacle (Frady et al., 1994; Kastelein et al., 1995). Furthermore, there is field evidence that some odontocetes have demonstrated avoidance to objects that have a similar TS as a 
floatline, but they tend to dive underneath such structures (Perrin and Hunter, 1972; Norris and Dohl, 1980; Perrin et al., 1994; Goodson and Mayo, 1995; Kastelein et al., 1995). Therefore, these animals may attempt to swim underneath the floatline and consequently get caught in the netting. If the entire netting was as obvious as the floatline, this could deter odontocetes from attempting to swim through the gillnet.

To put the identification of ideal resonators into perspective with conventional gillnets, the potential detection distances of modified gillnets were calculated. These models are based on several assumptions and serve mainly to be able to compare previous measurements to potential applications of the ideal reflectors. The spheres identified in this study, exhibit a similar TS as the floats of a gillnet and have, at least when attached close enough to each other, the same detection distance as the equivalent length of a floatline. Therefore, the spheres have the potential to make the whole netting area as obvious as the floatand leadlines. To achieve this, the distance between the spheres should be smaller than $0.5 \mathrm{~m}$ for odontocetes echolocating around $130 \mathrm{kHz}$. In this model, we considered consistently the same ensonified area $\left(0.36 \mathrm{~m}^{2}\right)$ in order to be comparable to previous work (Kastelein et al., 2000). Due to the nature of an area target, such as a gillnet, the ensonified area would increase with increasing distance. This, in turn, renders the TS larger as more spheres can be ensonified simultaneously. As this is a recursive process, the ensonified area was kept constant to be comparable to previous work, where the same issue is present. However, when the porpoise gets closer to the net, fewer spheres are ensonified, rendering it less visible. This counterintuitive circumstance is met by keeping the area constant to get be able to compare the nets. Therefore, in reality, the gillnet equipped with spheres will be even more acoustically visible than shown here, as more spheres are ensonified simultaneously.

When taking into account that the animal is not always perfectly perpendicular to the net when it echolocates, the TS decreases, but is still higher than regular gillnets. It is possible to improve the acoustic visibility of gillnets with small and neutrally buoyant spheres for a broad range of echolocating frequencies. The main challenge is now to identify optimal attachment patterns of these objects in the gillnet (e.g., distance between spheres) to be detected as an impenetrable obstacle. Increased detection ranges aside, another important goal of modifying gillnets with acrylic spheres is to alter the perceived acoustic image of the net in such a way that it resembles a wall-like structure. To prevent the animal from swimming through two objects adjacent to each other, the objects should be less than $0.5 \mathrm{~m}$ apart (Nakamura et al., 1998).

Klinowska et al. (1991) has already used acoustically reflective objects to "fill in" the space between floatline and leadline, which was visualized using side-scan sonar. Nevertheless, in this case the objects were large (max length $67 \mathrm{~mm}$, diameter $33 \mathrm{~mm}$ ) and spaced at a rather large distance $(2 \mathrm{~m})$. The sonar images (Figure 11) of a gillnet with $8 \mathrm{~mm}$ acrylic spheres attached at a distance of $0.3 \mathrm{~m}$ demonstrate clearly the improved visibility of the gillnet structure with spheres compared with standard gillnets. The echo of the attached spheres is almost as strong as the echo of the gillnet's floatline and leadline.

For the first time, an object was systematically identified and experimentally verified that substantially increases the detectability of gillnets, while meeting basic practical requirements for a low-tech fishery, such as small size and neutral buoyancy. Therefore, we see much potential in using small, acoustically reflective spheres to reduce the bycatch of several odontocetes species.

Nevertheless, the effectiveness of a passive reflector requires that odontocetes echolocate frequently - including in the direction of the net - and that they do not mistake the additional objects for prey. When comparing the sonar image of a gillnet to the sonar image of a shoal of fish (Figure 11 and Supplementary Figure 7) the porpoise might be unable to distinguish between the gillnet and the shoal of fish in individuals pings. However, harbor porpoises scan their environment with head movements and should thus be able to determine the beginning and end of a fish shoal, while the gillnet with acrylic spheres is a wall-like structure with a likely artificial image that they can swim along or swim over. Additionally, echograms from vessels are taken from a driving ship viewing toward the bottom, while the porpoise would be swimming perpendicularly to the shoal, thus the perceived image might be different compared to the view from the surface. While it may still be the case that individual spheres attached to the netting are mistaken for food, the entire image is unlikely to be mistaken for a large shoal of fish. Additionally, harbor porpoises have shown to react strongly to moving prey while foraging (Feldskov Hansen et al., 2017), which is not the case with a static net. How porpoises ultimately perceive their environment remains unclear, thus it is vital to investigate their reaction to modified gillnets through behavioral experiments.

Despite the fact that harbor porpoises forage, and thus echolocate, almost continuously (Wisniewska et al., 2016), there might be also periods of silence and other odontocete species might echolocate more frequently than others (Dawson, 1991; Akamatsu et al., 2007; Sørensen et al., 2018). To improve the effectiveness of gillnets with improved acoustic visibility, it might be necessary to combine the passive reflectors with active devices that send a "wake-up" call to the odontocete (Goodson, 1997). Such devices are currently being developed and tested for harbor porpoises in the Baltic Sea (Culik et al., 2015).

As demonstrated, it is possible to identify an optimal sphere with a diameter smaller than $20 \mathrm{~mm}$ for species that echolocate at frequencies higher than $40 \mathrm{kHz}$. For other species, the sphere size needs to be larger.

Several further steps are required prior to a widespread application of gillnets modified with acrylic glass spheres in the commercial gillnet fishery. Nevertheless, this study provides the essential basis for further development. Therefore, the next logical steps would be:

(a) the experimental verification of the estimated TS of a gillnet with acrylic spheres. Ideally, these experiments account for different attachment patterns of spheres to the gillnet, as well as different acoustical angles of approach and the aperture of the sonar beam; 
(b) a behavioral experiment to describe the difference in reaction of odontocete species in relation to modified and standard gillnets. These experiments require both visual and acoustic observation in order to describe the changes in swimming path and echolocating behavior;

(c) tests of net behavior with acrylic pearls attached, e.g., in a flume tank;

(d) a catch and bycatch comparison experiment in the commercial fishery;

(e) the development of automated processes to produce gillnets with spheres to provide cost-effective modified gillnets to the commercial fishery.

\section{DATA AVAILABILITY STATEMENT}

All datasets generated for this study are included in the article/Supplementary Material.

\section{AUTHOR CONTRIBUTIONS}

IK, IS, AS, JC, and DS acquired the data via simulation, modeling or measurements. All authors wrote the manuscript.

\section{REFERENCES}

Abts, G. (2016). Kunststoff-Wissen für Einsteiger, 3ed Edn. Munich: Hanser.

Accobams. (2001). Agreement on the Conservation of Cetaceans of the Black Sea, Mediterranean Sea and Contiguous Atlantic Area. Bonn: ACCOBAMS.

Ainslie, M. A., and McColm, J. G. (1998). A simplified formula for viscous and chemical absorption in sea water. J. Acoust. Soc. Am. 103, 1671-1672. doi: $10.1121 / 1.421258$

Akamatsu, T., Teilmann, J., Miller, L. A., Tougaard, J., Dietz, R., Wang, D., et al. (2007). Comparison of echolocation behaviour between coastal and riverine porpoises. Deep Sea Res. Part II Top. Stud. Oceanogr. 54, 290-297. doi: 10.1016/ j.dsr2.2006.11.006

ASCOBANS (1992). Agreement on the Conservation of Small Cetaceans of the Baltic, North East Atlantic, Irish and North Seas. Bonn: ACCOBAMS.

Atkins, P., Francis, D. T., and Foote, K. G. (2008). Calibration of broadband sonar systems using multiple standard targets. J. Acoust. Soc. Am. 123, 3436-3436. doi: $10.1121 / 1.2934223$

Au, W. L., and Jones, L. (1991). Acoustic reflectivity of nets: implications concerning incidental take of dolphins. Mar. Mamm. Sci. 7, 258-273. doi: 10.1111/j.1748-7692.1991.tb00101.x

Au, W. W. L., Benoit-Bird, K. J., and Kastelein, R. A. (2007). Modeling the detection range of fish by echolocating bottlenose dolphins and harbor porpoises. J. Acoust. Soc. Am. 121, 3954-3962. doi: 10.1121/1.2734487

Bordino, P., Albareda, D., Palmerio, A., Mendez, M., and Botta, S. (2002). Reducing incidental mortalitiy of Franciscana dolphin Pontoporia Blainvillei with acoustic warning devices attached to fishing nets. Mar. Mamm. Sci. 18, 833-842. doi: 10.1111/j.1748-7692.2002.tb01076.x

Bordino, P., Mackay, A., Werner, T., Northridge, S., and Read, A. (2013). Franciscana bycatch is not reduced by acoustically reflective or physically stiffened gillnets. Endanger. Species Res. 21, 1-12. doi: 10.3354/esr00503

Burkhart, S. M., and Slooten, E. (2003). Population viability analysis for Hector's dolphin (Cephalorhynchus hectori): a stochastic population model for local populations. N. Z. J. Mar. Freshw. Res. 37, 553-566. doi: 10.1080/00288330.2003. 9517189

Carlström, J., Berggren, P., and Tregenza, N. J. C. (2009). Spatial and temporal impact of pingers on porpoises. Can. J. Fish. Aquat. Sci. 66, 72-82. doi: 10.1139/ f08-186

\section{FUNDING}

This work was funded by the German Federal Agency for Nature Conservation (Bundesamt für Naturschutz, project no. 3516821300, Entwicklung von alternativen Managementansätzen und Fangtechniken zur Minimierung der Konflikte zwischen Stellnetzfischerei und Naturschutzzielen in der deutschen AWZ der Ostsee STELLA).

\section{ACKNOWLEDGMENTS}

We thank C. Zimmermann, U. Krumme, B. Anthony, and the reviewers for helpful comments on this manuscript.

\section{SUPPLEMENTARY MATERIAL}

The Supplementary Material for this article can be found online at: https://www.frontiersin.org/articles/10.3389/fmars. 2020.00539/full\#supplementary-material

Carretta, J. V., and Barlow, J. (2011). Long-term effectiveness, failure rates, and "dinner bell" properties of acoustic pingers in a gillnet fishery. Mar. Technol. Soc. J. 45, 7-19. doi: 10.4031/mtsj.45.5.3

Comsol Multiphysics ${ }^{\circledR}$ (2018). Stockholm. Sweden: COMSOL AB.

Cox, T. M., Read, A. J., Solow, A., and Tregenza, N. (2001). Will harbour porpoises (Phocoena phocoena) habituate to pingers? J. Cetacean Res. Manag. 3 , 81-86.

Crespo, E. A. (2018). “Franciscana dolphin: pontoporia blainvillei,” in Encyclopedia of Marine Mammals, 3rd End Edn, eds B. Würsig, J. G. M. Thewissen, and K. M. Kovacs (Cambridge, MA: Academic Press), 388-392.

Culik, B., von Dorrien, C., Müller, V., and Conrad, M. (2015). Synthetic communication signals influence wild harbour porpoise (Phocoena phocoena) behaviour. Bioacoustics 24, 201-221. doi: 10.1080/09524622.2015.102 3848

D'agrosa, C., Lennert-Cody, C. E., and Vidal, O. (2000). Vaquita bycatch in Mexico's artisanal gillnet fisheries: driving a small population to extinction. Conserv. Biol. 14, 1110-1119. doi: 10.1046/j.1523-1739.2000.98191.x

Dauchez, N., Etchessahar, M., and Sahraoui, S. (2002). On Measurement of Mechanical Properties of Sound Absorbing Materials. Available online at: https: //hal.archives-ouvertes.fr/hal-00331372 (accessed July 18, 2019).

Dawson, S., Northridge, S. P., Waples, D., and Read, A. (2013). To ping or not to ping: the use of active acoustic devices in mitigating interactions between small cetaceans and gillnet fisheries. Endanger. Species Res. 19, 201-221. doi: $10.3354 /$ esr00464

Dawson, S. M. (1991). Modifying gillnets to reduce entanglement of cetaceans. Mar. Mamm. Sci. 7, 274-282. doi: 10.1111/j.1748-7692.1991.tb00102.x

Echoview Software Pty Ltd (2015). Echoview Software Pty Ltd. Hobart: Echoview Software Pty Ltd.

EEC (1992). Council Directive 92/43/EEC of 21 May 1992 on the Conservation of Natural Habitats and of Wild Fauna and Flora. Available online at: http: //data.europa.eu/eli/dir/1992/43/oj/eng (accessed August 28, 2019).

Estes, J. A., Terborgh, J., Brashares, J. S., Power, M. E., Berger, J., Bond, W. J., et al. (2011). Trophic downgrading of planet earth. Science 333, 301-306. doi: 10.1126/science. 1205106

Feldskov Hansen, K., Hojer Kristensen, J., Prömper, D., and Wahlberg, M. (2017). Predator-prey Interactions between Harbour Porpoieses and Fish observed with a Drone. Middelfart: Poster at ECS conference. 
Foote, K. G. (1982). Optimizing copper spheres for precision calibration of hydroacoustic equipment. J. Acoust. Soc. Am. 71, 742-747. doi: 10.1121/1. 387497

Foote, K. G. (1983). Maintaining precision calibrations with optimal copper spheres. J. Acousti. Soc. Am. 73, 1054-1063. doi: 10.1121/1.389153

Frady, T., Northridge, S., and Smith, T. S. (1994). Identifying Potential Modifications to sink Gillnet Gear to Reduce Harbor Porpoise Bycatch. Silver Spring, MA: NOAA/NEFSC.

Goodson, A. D. (1997). Developing deterrent devices designed to reduce the mortality of small cetaceans in commercial fishing nets. Mar. Freshw. Behav. Physiol. 29, 211-236. doi: 10.1080/10236249709379007

Goodson, A. D., and Mayo, R. H. (1995). "Interactions between free-ranging bottlenose dolphins, Tursiops truncatus, and passive acoustic gillnet deterrent devices," in Sensory Systems of Aquatic Mammals Proceedings of the "Marine Mammal Sensory Symposium., eds R. A. Kastelein, J. A. Thomas, and P. E. Nachtigall (Woerden: De Spil Publishers).

Gormley, A. M., Slooten, E., Dawson, S., Barker, R. J., Rayment, W., du Fresne, S., et al. (2012). First evidence that marine protected areas can work for marine mammals. J. Appl. Ecol. 49, 474-480. doi: 10.1111/j.1365-2664.2012. 02121.x

Harrop, S. R. (2003). From cartel to conservation and on to compassion: animal welfare and the international whaling commission. J. Int. Wildlife Law Policy 6, 79-104. doi: 10.1080/713778532

He, P. (ed.) (2010). Behavior of Marine Fishes. Ames: Wiley-Blackwell.

Helcom. (2013). HELCOM Red List of Baltic Sea species in Danger of Becoming Extinct. Available online at: http://www.helcom.fi/Lists/Publications/BSEP140. pdf (accessed July 3, 2019).

Hembree, D., and Harwood, M. B. (1987). Pelagic Gillnet Modification Trials in Northern Australian Seas. Cambridge, MA: IWC.

IUCN (2019). The IUCN Red List of Threatened Species Version 2019-1. Available online at: http://www.iucnredlist.org (Accessed July 8, 2019).

IWC (2018). Resolutions Adopted at the 67th Meeting. Nairobi: IWC.

IWC (2019). Report of the IWC Scientific Committee. Nairobi: IWC.

Jensen, F. H., Rocco, A., Mansur, R. M., Smith, B. D., Janik, V. M., and Madsen, P. T. (2013). Clicking in shallow rivers: short-range echolocation of irrawaddy and ganges river dolphins in a shallow, acoustically complex habitat. PLoS One 8:e59284. doi: 10.1371/journal.pone.0059284

Kastelein, R., Au, W. W., and de Haan, D. (2000). Detection distances of bottomset gillnets by harbour porpoises (Phocoena phocoena) and bottlenose dolphins (Tursiops truncatus). Mar. Environ. Res. 49, 359-375. doi: 10.1016/s01411136(99)00081-1

Kastelein, R. A., Au, W. W. L., Rippe, H. T., and Schooneman, N. M. (1999). Target detection by an echolocating harbor porpoise (Phocoena phocoena). J. Acoust. Soc. Am. 105, 2493-2498. doi: 10.1121/1.426951

Kastelein, R. A., de Haan, D., and Staal, C. (1995). "Behaviour of Harbour porpoises (Phocoena phocoena) in response to ropes," in Harbour Porpoises, Laboratory Studies to Reduce Bycatch, eds P. E. Nachtigall, J. Lien, W. W. L. Au, and A. J. Read (Woerden: De Spil Publishers), 69-90.

Kastelein, R. A., Hagedoorn, M., Au, W. W. L., and de Haan, D. (2003). Audiogram of a striped dolphin (Stenella coeruleoalba). J. Acoust. Soc. Am. 113, 1130-1137. doi: $10.1121 / 1.1532310$

Kinsler, L. E., Frey, A. R., Coppens, A. B., and Sanders, J. V. (eds) (2000). Fundamentals of Acoustics, 4th Edn. New York, NY: Wiley \& Sons.

Klinowska, M., Goodson, A. D., and Bloom, P. (1991). Progress in the Development of Efficient Warning Devices to Prevent the Entrapment of Cetaceans (Dolphins, Porpoises and Whales) in Fishing Nets. Westminster: ICES.

Koschinski, S., and Pfander, A. (2009). "By-catch of harbour porpoises (Phocoena phocoena) in the baltic coastal waters of angeln and schwansen (SchleswigHolstein, Germany)," in ASCOBANS 16th Advisory Committee Meeting, Brugge.

Kraus, S. D., Read, A. J., Solow, A., Baldwin, K., Spradlin, T., Anderson, E., et al. (1997). Acoustic alarms reduce porpoise mortality. Nature 388:525. doi: 10. $1038 / 41451$

Ladegaard, M., Jensen, F. H., Freitas, M., de, Silva, V. M. F., and Madsen, P. T. (2015). Amazon river dolphins (Inia geoffrensis) use a high-frequency short-range biosonar. J. Exp. Biol. 218, 3091-3101. doi: 10.1242/jeb.12 0501
Larsen, F., and Eigaard, O. R. (2014). Acoustic alarms reduce bycatch of harbour porpoises in Danish North Sea gillnet fisheries. Fisher. Res. 153, 108-112. doi: 10.1016/j.fishres.2014.01.010

Larsen, F., Eigaard, O. R., and Tougaard, J. (2007). Reduction of harbour porpoise (Phocoena phocoena) bycatch by iron-oxide gillnets. Fisher. Res. 85, 270-278. doi: 10.1016/j.fishres.2007.02.011

Lewison, R. L., Crowder, L. B., Wallace, B. P., Moore, J. E., Cox, T., Zydelis, R., et al. (2014). Global patterns of marine mammal, seabird, and sea turtle bycatch reveal taxa-specific and cumulative megafauna hotspots. Proc. Natl. Acad. Scie. U.S.A. 111, 5271-5276. doi: 10.1073/pnas.1318960111

Lovatt, A. M., Shercliff, H. R., and Withers, P. J. (2000). Material Selection and Processing. Cambridge, MA: Design, Ltd.

Mackay, A. I. (2011). An Investigation of Factors Related to the Bycatch of Small Cetaceans in Fishing Gear. Ph D Thesis, University of St, Andrews.

MacLennan, D., Fernandes, P. G., and Dalen, J. (2002). A consistent approach to definitions and symbols in fisheries acoustics. ICES J. Mar. Sci. 59, 365-369. doi: $10.1006 /$ jmsc.2001.1158

MacLennan, D. N. (1981). The theory of solid spheres as sonar calibration targets. Scottish Fish. Res. Rep. 22:18.

Mangel, J. C., Alfaro-Shigueto, J., Witt, M. J., Hodgson, D. J., and Godley, B. J. (2013). Using pingers to reduce bycatch of small cetaceans in Peru's small-scale driftnet fishery. Oryx 47, 595-606. doi: 10.1017/s0030605312000658

Marine Mammal Protection Act (1972). Marine Mammal Protection Act of the United States. Available online at: https:/www.govinfo.gov/content/pkg/ STATUTE-86/pdf/STATUTE-86-Pg1027.pdf (accessed August 28, 2019).

Millennium Ecosystem Assessment (2005). Ecosystems and Human Well-Being: Synthesis. Washington, DC: Island Press.

Mooney, T. A., Au, W. W., Nachtigall, P. E., and Trippel, E. A. (2007). Acoustic and stiffness properties of gillnets as they relate to small cetacean bycatch. ICES J. Mar. Sci. Conseil 64, 1324-1332. doi: 10.1093/icesjms/fsm135

Mooney, T. A., Nachtigall, P. E., and Au, W. W. (2004). Target strength of a nylon monofilament and an acoustically enhanced gillnet: predictions of biosonar detection ranges. Aquat. Mamm. 30, 220-226. doi: 10.1578/am.30.2.2004.220

Morisaka, T., and Connor, R. C. (2007). Predation by killer whales (Orcinus orca) and the evolution of whistle loss and narrow-band high frequency clicks in odontocetes. J. Evol. Biol. 20, 1439-1458. doi: 10.1111/j.1420-9101.2007. 01336.x

Murray, K., Read, A., and Solow, A. (2000). The use of time/area closures to reduce bycatches of harbour porpoises: lessons from the Gulf of Maine sink gillnet fishery. J. Cetac. Res. Manag. 2, 135-141.

Nakamura, K., Akamatsu, T., Goodson, A. D., Kagoshima, K., and Shimazaki, K. (1998). Gillnet passive acoustic deterrents: investigating inter-reflector spacings with a harbor porpoise Phocoena phocoena. Fisher. Sci. 64, 648-649. doi: 10. 2331/fishsci.64.648

Nielsen, T. P., Wahlberg, M., Heikkilä, S., Jensen, M., Sabinsky, P., and Dabelsteen, T. (2012). Swimming patterns of wild harbour porpoises Phocoena phocoena show detection and avoidance of gillnets at very long ranges. Mar. Ecol. Prog. Ser. 453, 241-248. doi: 10.3354/meps09630

Norris, K. S., and Dohl, T. P. (1980). Behavior of the Hawaiian spinner dolphin. Stenella Longirostris. Fisher. Bull. 77, 829-849.

Peddemors, V., Cockcroft, V., and Wilson, R. B. (1991). Incidental Dolphin Mortality in the Natal Shark Nets: A Pre-Liminary Report on Prevention Measures. Nairobi: United States Environmental Programme.

Pence, E. A. (1986). Monofilament Gill Net Acoustic Study. Seattle, WA: University of Washington.

Perrin, W. F., Donovan, G. P., and Barlow, J. (eds) (1994). Gillnets and Cetaceans: Incorporating the Proceedings of the Symposium and Workshop on the Mortality of Cetaceans in Passive Fishing Nets and Traps. Cambridge, MA: International Whaling Commission.

Perrin, W. F., and Hunter, J. R. (1972). Escape behavior of the Hawaiian Spinner porpoise (Stenella cf. S. longirostris). Fisher. Bull. 70, 49-60.

Popov, I., and Sabev, S. (2016). "Comparative analysis of static and dynamic elastic modulus of polymer concrete composites," in Scientific Proceedings Xiii, Varna, 71-74.

Pritz, T. (1994). Dynamic young's modulus and loss factor of plastic foams for impact sound isolation. J. Sound Vib. 178, 315-322. doi: 10.1006/jsvi.1994.1488 
Rankin, S., Oswald, J., Barlow, J., and Lammers, M. (2007). Patterned burstpulse vocalizations of the northern right whale dolphin, Lissodelphis borealis. J. Acoust. Soc. Am. 121, 1213-1218. doi: 10.1121/1.2404919

Read, A. J., Drinker, P., and Northridge, S. (2006). Bycatch of Marine Mammals in U.S. and global fisheries. Conserv. Biol. 20, 163-169. doi: 10.1111/j.1523-1739. 2006.00338.x

Reeves, R., McClellan, K., and Werner, T. (2013). Marine mammal bycatch in gillnet and other entangling net fisheries, 1990 to 2011. Endanger. Species Res. 20, 71-97. doi: 10.3354/esr00481

Reeves, R. R., Smith, B. D., Crespo, E. A., and Notarbartolo di Sciara, G. (eds) (2003). Dolphins, Whales and Porpoises: 2002 - 2010 Conservation Action Plan for the World's Cetaceans. Gland: IUCN.

Sabbagh, J., Vreven, J., and Leloup, G. (2002). Dynamic and static moduli of elasticity of resin-based materials. Dent. Mater. 18, 64-71. doi: 10.1016/S01095641(01)00021-5

Savina, E., Krag, L. A., and Madsen, N. (2018). Developing and testing a computer vision method to quantify 3D movements of bottom-set gillnets on the seabed. ICES J. Mar. Sci. 75, 814-824. doi: 10.1093/icesjms/fsx194

Sheng, J., and Hay, A. E. (1993). Spherical wave backscatter from straight cylinders: thin-wire standard targets. J. Acoust. Soc. Am. 94, 2756-2765. doi: 10.1121/1. 407359

Sørensen, P. M., Wisniewska, D. M., Jensen, F. H., Johnson, M., Teilmann, J., and Madsen, P. T. (2018). Click communication in wild harbour porpoises (Phocoena phocoena). Sci. Rep. 8:97. doi: 10.1038/s41598-018-28022-8

Sullivan-Silva, K. B. (1989). Underwater Acoustic Scattering From Spherical Particulates and Bubbles. Newport, RI: Naval Underwater Systems Center.

Thorpe, C. W., and Dawson, S. M. (1991). Automatic measurement of descriptive features of Hector's dolphin vocalizations. J. Acoust. Soc. Am. 89, 435-443. doi: 10.1121/1.400477

Tonay, A. M. (2016). Estimates of cetacean by-catch in the turbot fishery on the Turkish Western Black Sea Coast in 2007 and 2008. J. Mar. Biol. Asso. U. K. 96, 993-998. doi: 10.1017/S0025315416000060

Trippel, E. A., Holy, N. L., Palka, D. L., Shepherd, T. D., Melvin, G. D., and Terhune, J. M. (2003). Nylon barium sulphate gillnet reduces porpoise and seabird mortality. Mar. Mamm. Sci. 19, 240-243. doi: 10.1111/j.1748-7692. 2003.tb01106.x
Trippel, E. A., Wang, J. Y., Strong, M. B., Carter, L. S., and Conway, J. D. (1996). Incidental mortality of harbour porpoise (Phocoena phocoena) by the gill-net fishery in the lower Bay of Fundy. Canad. J. Fish. Aquat. Sci. 53, 1294-1300. doi: 10.1139/f96-060

Turvey, S. T., Pitman, R. L., Taylor, B. L., Barlow, J., Akamatsu, T., Barrett, L. A., et al. (2007). First human-caused extinction of a cetacean species? Biol. Lett. 3 , 537-540. doi: 10.1098/rsbl.2007.0292

Villadsgaard, A., Wahlberg, M., and Tougaard, J. (2007). Echolocation signals of wild harbour porpoises, Phocoena phocoena. J. Exp. Biol. 210, 56-64. doi: $10.1242 /$ jeb.02618

Vinther, M., and Larsen, F. (2004). Updated estimates of harbour porpoise (Phocoena phocoena) bycatch in the Danish North Sea bottom-set gillnet fishery. J. Cetac. Res. Manag. 6, 19-24.

Wahlberg, M., Jensen, F. H., Aguilar Soto, N., Beedholm, K., Bejder, L., Oliveira, C., et al. (2011). Source parameters of echolocation clicks from wild bottlenose dolphins (Tursiops aduncus and Tursiops truncatus). J. Acoust. Soc. Am. 130, 2263-2274. doi: 10.1121/1.3624822

Welsby, V. G., and Hudson, J. E. (1972). Standard small targets for calibrating underwater sonars. J. Sound Vib. 20, 399-406. doi: 10.1016/0022-460X(72) 90619-0

Wisniewska, D. M., Johnson, M., Teilmann, J., Rojano-Doñate, L., Shearer, J., Sveegaard, S., et al. (2016). Ultra-high foraging rates of harbor porpoises make them vulnerable to anthropogenic disturbance. Curr. Biol. 26, 1441-1446. doi: 10.1016/j.cub.2016.03.069

Conflict of Interest: The authors declare that the research was conducted in the absence of any commercial or financial relationships that could be construed as a potential conflict of interest.

Copyright (c) 2020 Kratzer, Schäfer, Stoltenberg, Chladek, Kindt-Larsen, Larsen and Stepputtis. This is an open-access article distributed under the terms of the Creative Commons Attribution License (CC BY). The use, distribution or reproduction in other forums is permitted, provided the original author(s) and the copyright owner(s) are credited and that the original publication in this journal is cited, in accordance with accepted academic practice. No use, distribution or reproduction is permitted which does not comply with these terms. 